\title{
Scaling Analysis
}

Techniques to Establish Experimental

Infrastructure for

Component, Subsystem,

and Integrated System

Testing

Piyush Sabharwall, James E. O'Brien, Michael G. McKellar, Gregory K. Housley, Shannon M. Bragg-Sitton, and Richard D. Boardman

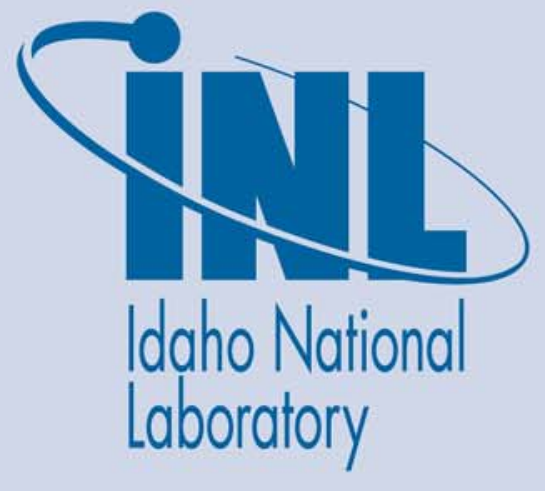

March 2015

The INL is a U.S. Department of Energy National Laboratory operated by Battelle Energy Alliance 
INL/EXT-15-34456

Revision 0

\section{Scaling Analysis Techniques to Establish Experimental Infrastructure for Component, Subsystem, and Integrated System Testing}

Piyush Sabharwall, James E. O'Brien, Michael G. McKellar, Gregory K. Housley, Shannon M. Bragg-Sitton, and Richard D. Boardman

March 2015

Idaho National Laboratory Nuclear Science and Technology

Idaho Falls, Idaho 83415

http://www.inl.gov

Prepared for the

U.S. Department of Energy

Office of Nuclear Energy

Under DOE Idaho Operations Office

Contract DE-AC07-05ID14517 


\section{DISCLAIMER}

This information was prepared as an account of work sponsored by an agency of the U.S. Government. Neither the U.S. Government nor any agency thereof, nor any of their employees, makes any warranty, expressed or implied, or assumes any legal liability or responsibility for the accuracy, completeness, or usefulness, of any information, apparatus, product, or process disclosed, or represents that its use would not infringe privately owned rights. References herein to any specific commercial product, process, or service by trade name, trade mark, manufacturer, or otherwise, does not necessarily constitute or imply its endorsement, recommendation, or favoring by the U.S. Government or any agency thereof. The views and opinions of authors expressed herein do not necessarily state or reflect those of the U.S. Government or any agency thereof. 


\section{SUMMARY}

Hybrid energy system research has the potential to expand the application for nuclear reactor technology beyond electricity. The purpose of this research is to reduce both technical and economic risks associated with energy systems of the future. Nuclear hybrid energy systems (NHES) mitigate the variability of renewable energy sources, provide opportunities to produce revenue from different product streams, and avoid capital inefficiencies by matching electrical output to demand by using excess generation capacity for other purposes when it is available. An essential step in the commercialization and deployment of this advanced technology is scaled testing to demonstrate integrated dynamic performance of advanced systems and components when risks cannot be mitigated adequately by analysis or simulation. Further testing in a prototypic environment is needed for validation and higher confidence.

This research supports the development of advanced nuclear reactor technology and NHES, and their adaptation to commercial industrial applications that will potentially advance U.S. energy security, economy, and reliability and further reduce carbon emissions. Experimental infrastructure development for testing and feasibility studies of coupled systems can similarly support other projects having similar developmental needs and can generate data required for validation of models in thermal energy storage and transport, energy, and conversion process development. Experiments performed in the Systems Integration Laboratory will acquire performance data, identify scalability issues, and quantify technology gaps and needs for various hybrid or other energy systems.

This report discusses detailed scaling (component and integrated system) and heat transfer figures of merit that will establish the experimental infrastructure for component, subsystem, and integrated system testing to advance the technology readiness of components and systems to the level required for commercial application and demonstration under NHES. 


\section{CONTENTS}

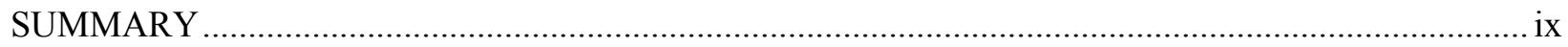

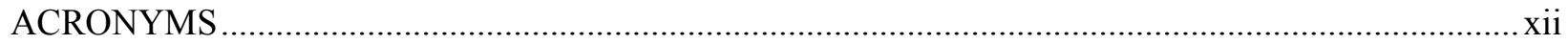

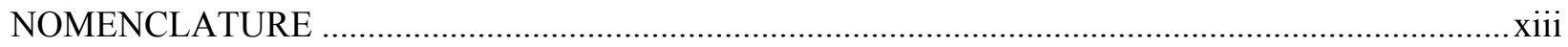

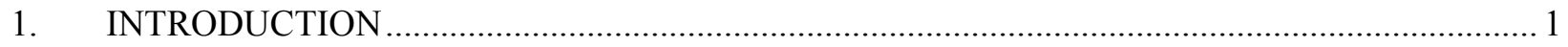

2. OVERVIEW OF THE SYSTEM INTEGRATION LABORATORY (TEST FACILITY).............. 4

3. SYSTEM INTEGRATION LABORATORY FACILITIES AND RESEARCH

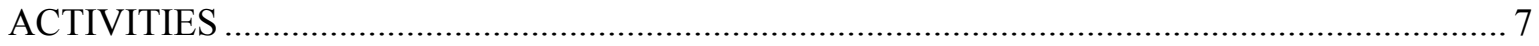

3.1 Multi-Fluid, Multi-Loop Thermal Hydraulic Test Facility .............................................. 7

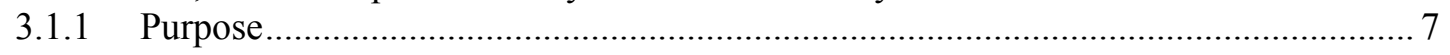

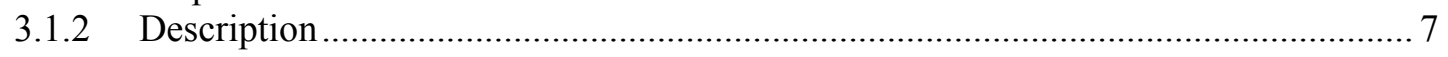

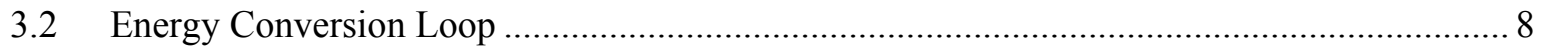

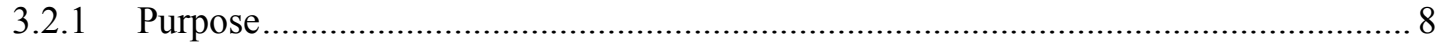

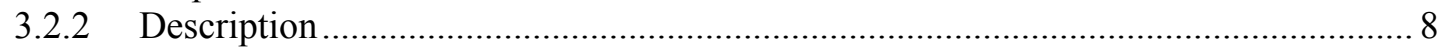

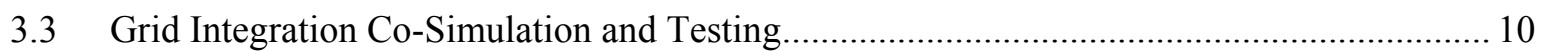

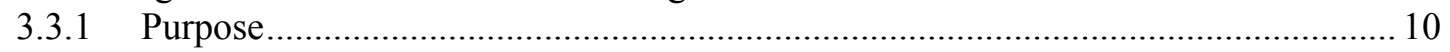

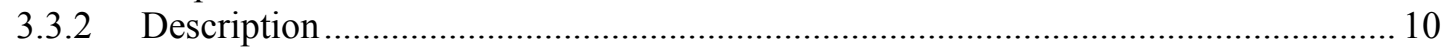

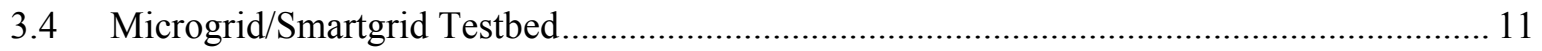

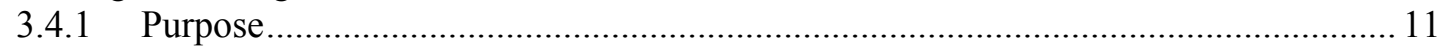

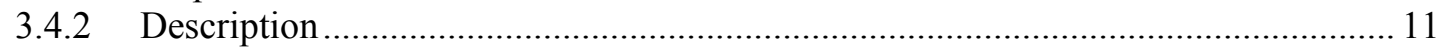

3.5 Electrical Vehicle Battery Indirect Charging Test Station .............................................. 13

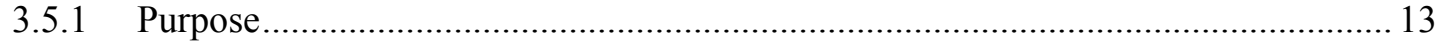

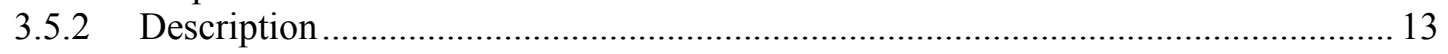

4. DEVELOPMENT OF FIGURES OF MERIT FOR COOLANT

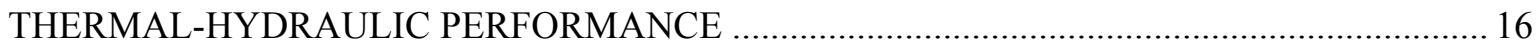

4.1 Heat Transfer Performance Factor: Figures of Merit for Heat Transfer Performance

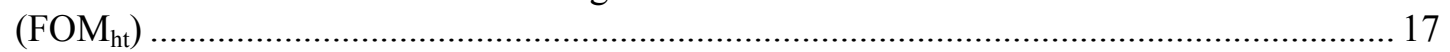

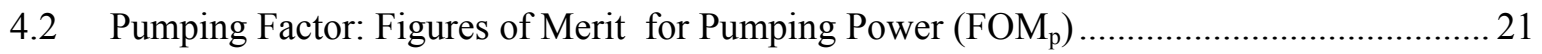

4.3 Coolant Volume Factor: Figures of Merit for Coolant Volume $\left(\mathrm{FOM}_{\mathrm{cv}}\right)$........................... 22

4.4 Pipe Material Volume Factor: Figures of Merit for Coolant Containment Volume

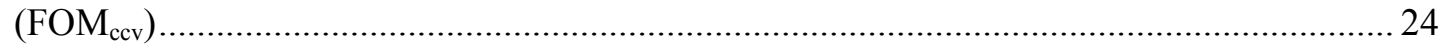

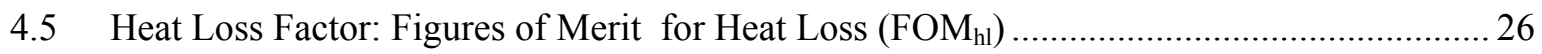

4.6 Temperature Drop Factor: Figures of Merit for Temperature Drop $\left(\mathrm{FOM}_{\mathrm{dt}}\right)$.................... 28

4.7 Summary of Figures of Merit for Heat Transfer Coolant ..................................................29

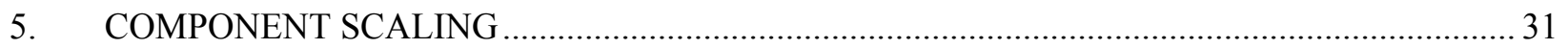

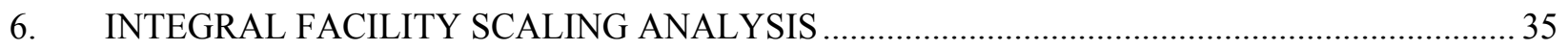

6.1 Phenomena Identification and Ranking Table Process .................................................... 36

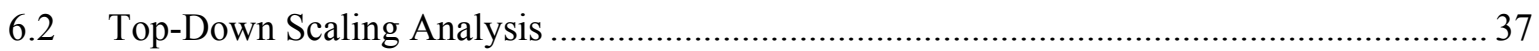

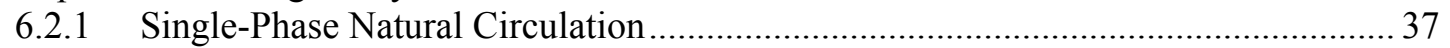


6.2.2 Two-Phase Natural Circulation.

6.2.3 Geometry-Level Governing Equations and Nondimensional Parameters ................ 45

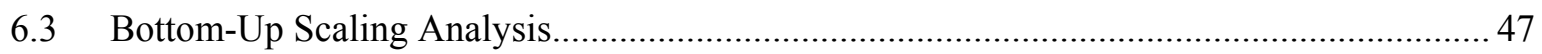

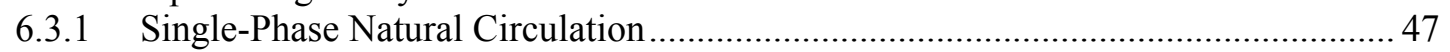

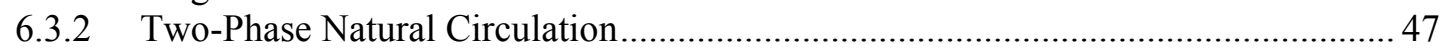

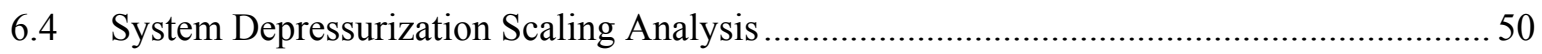

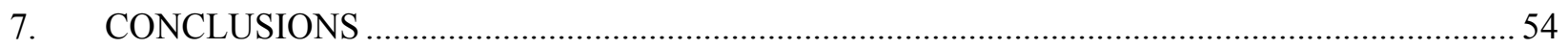

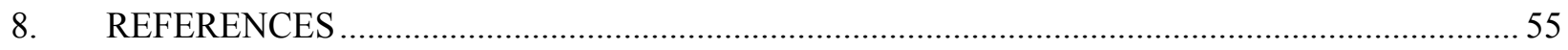

\section{FIGURES}

Figure 1. Generalized Nuclear hybrid energy system architecture (Bragg-Sitton et al. 2014) .................. 1

Figure 2. Energy Systems Laboratory preliminary highbay design layout.............................................. 5

Figure 3. Schematic of the proposed multi-fluid, multi-loop thermal hydraulic facility............................ 7

Figure 4. The energy conversion loop for the Phase I configuration ...................................................... 9

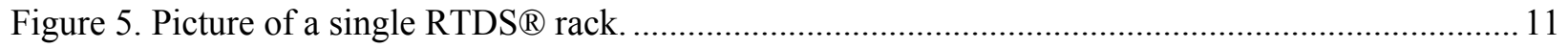

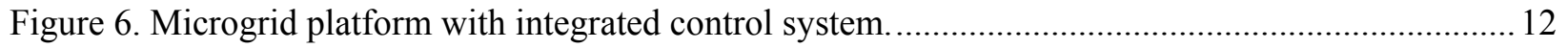

Figure 7. Electric Vehicle Charging Infrastructure Testing Facility ..................................................... 14

Figure 8. General thermal-hydraulic requirements for the intermediate coolant in advanced high

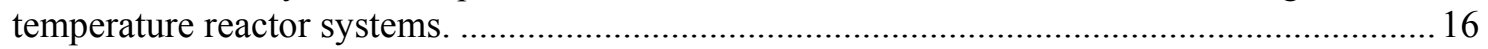

Figure 9. General configuration of an intermediate heat transfer loop. ................................................ 17

Figure 10. Geometry and input parameters for figures of merit development (heat transfer

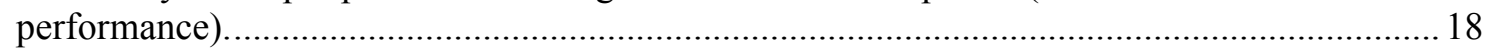

Figure 11. Simple illustration of a prototype and a model heat exchanger..............................................31

Figure 12. Power ratio as a function of break diameter. ....................................................................... 53

\section{TABLES}

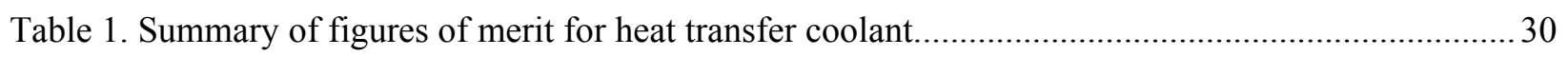

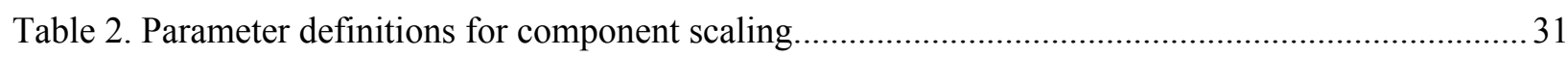




\section{ACRONYMS}

3D three-dimensional

AHTR Advanced High Temperature Reactor

ARTIST Advanced Reactor Technology Integral System Test (facility)

CHF critical Heat Flux

DOE Department of Energy

ECL Energy Conversion Loop

ESL Energy Systems Laboratory

FOM Figure of Merit

H2TS Hierarchical 2-Tiered Scaling

ICS Intelligent Control Systems

IHX Intermediate Heat Exchanger

INL Idaho National Laboratory

LDRD laboratory-directed research and development

NHES nuclear Hybrid Energy Systems

PIRT Phenomena Identification and Ranking Table

PWR Pressurized Water Reactor

RELAP5 Reactor Excursion and Leak Analysis Program (Version 5)

RTDS $^{\circledR} \quad$ Real-Time Digital Simulator

SHX Secondary Heat Exchanger

SIL Systems Integration Laboratory 


\section{NOMENCLATURE}

$a_{c} \quad$ cross-sectional area of core $\left(\mathrm{m}^{2}\right)$

$a_{b r k} \quad$ break flow area $\left(\mathrm{m}^{2}\right)$

$a_{i} \quad$ cross-sectional area of ith section $\left(\mathrm{m}^{2}\right)$

$A_{f} \quad$ flow area $\left(\mathrm{m}^{2}\right)$

$A_{R} \quad$ flow area scale ratio

$A_{s} \quad$ heat transfer surface area $\left(\mathrm{m}^{2}\right)$

$B i \quad$ Biot number

$C_{d} \quad$ orifice loss coefficient

$C_{p l} \quad$ constant pressure specific heat of liquid (J/kg K)

$C_{v l} \quad$ constant-volume specific heat $(\mathrm{J} / \mathrm{kg} \mathrm{K})$

$d_{h} \quad$ hydraulic diameter $(\mathrm{m})$

$d_{\text {pin }} \quad$ fuel rod diameter $(\mathrm{cm})$

$D_{b r k} \quad$ break diameter $(\mathrm{cm})$

D channel diameter (m)

$D_{h, m} \quad$ hydraulic diameter for the model (m)

$D_{h, p} \quad$ hydraulic diameter for the prototype (m)

e specific internal energy $(\mathrm{J} / \mathrm{kg})$

E energy (W)

$f \quad$ Darcy friction factor

$f_{T} \quad$ flow regime transition functional relationship

$F_{q} \quad$ axial heat flux distribution peaking factor

$\mathrm{Fr} \quad$ Froude number

$F O M_{t h}$ figure of merit for heat transfer performance

$F O M_{\text {th }}$ figure of merit for pumping power

$F O M_{c v}$ figure of merit for coolant volume

$F O M_{c c v}$ figure of merit for pipe structure volume

$F O M_{h l} \quad$ figure of merit for heat loss

$F O M_{d t} \quad$ figure of merit for temperature drop

$g \quad$ acceleration due to gravity $\left(\mathrm{m} / \mathrm{s}^{2}\right)$

$G \quad$ mass flux $\left(\mathrm{kg} / \mathrm{s} \mathrm{m}^{2}\right)$

Gr Grash of number

$h \quad$ specific enthalpy $(\mathrm{J} / \mathrm{kg})$

$h_{\text {conv }} \quad$ convective heat transfer coefficient $\left(\mathrm{W} / \mathrm{m}^{2} \mathrm{~K}\right)$ 


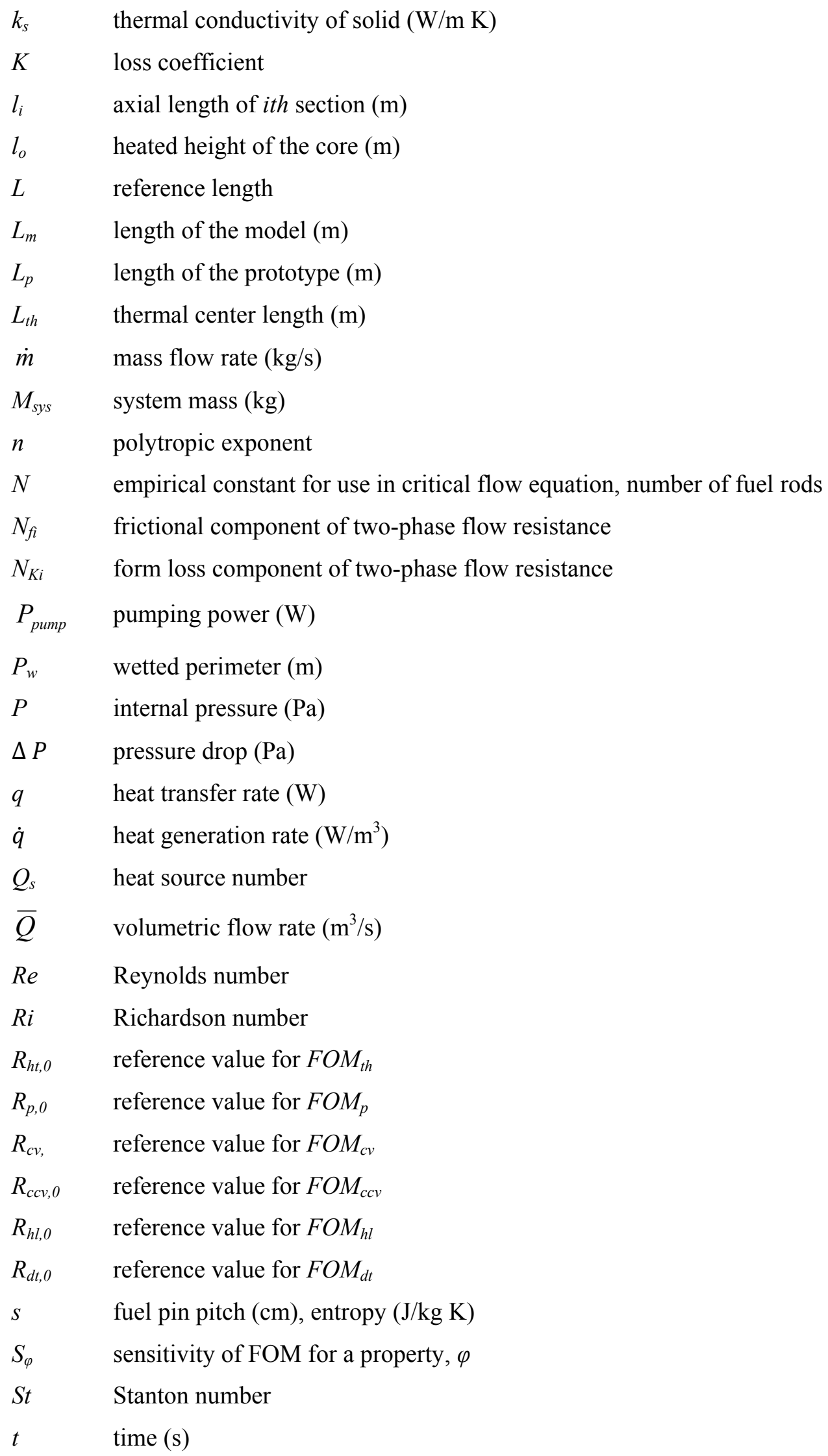




$\begin{array}{ll}T & \text { temperature }(\mathrm{K}) \\ \Delta T & \text { temperature difference }(\mathrm{K}) \\ T^{*} & \text { conduction time number } \\ u_{i} & \text { component velocity }(\mathrm{m} / \mathrm{s}) \\ u_{c o} & \text { core inlet velocity }(\mathrm{m} / \mathrm{s}) \\ u_{o} & \text { characteristic velocity for natural convection }(\mathrm{m} / \mathrm{s}) \\ U & \text { flow velocity }(\mathrm{m} / \mathrm{s}) \\ v & \text { specific volume }\left(\mathrm{m}^{3} / \mathrm{kg}\right) \\ V & \text { volume }\left(\mathrm{m}^{3}\right) \\ v_{g j} & \text { drift velocity }(\mathrm{m} / \mathrm{s}) \\ x & \text { vapor quality } \\ \mathrm{y} & \text { dimension normal to solid-fluid interface }(\mathrm{m}) \\ \mathrm{z} & \text { axial dimension }(\mathrm{m})\end{array}$

\section{Greek Letters}

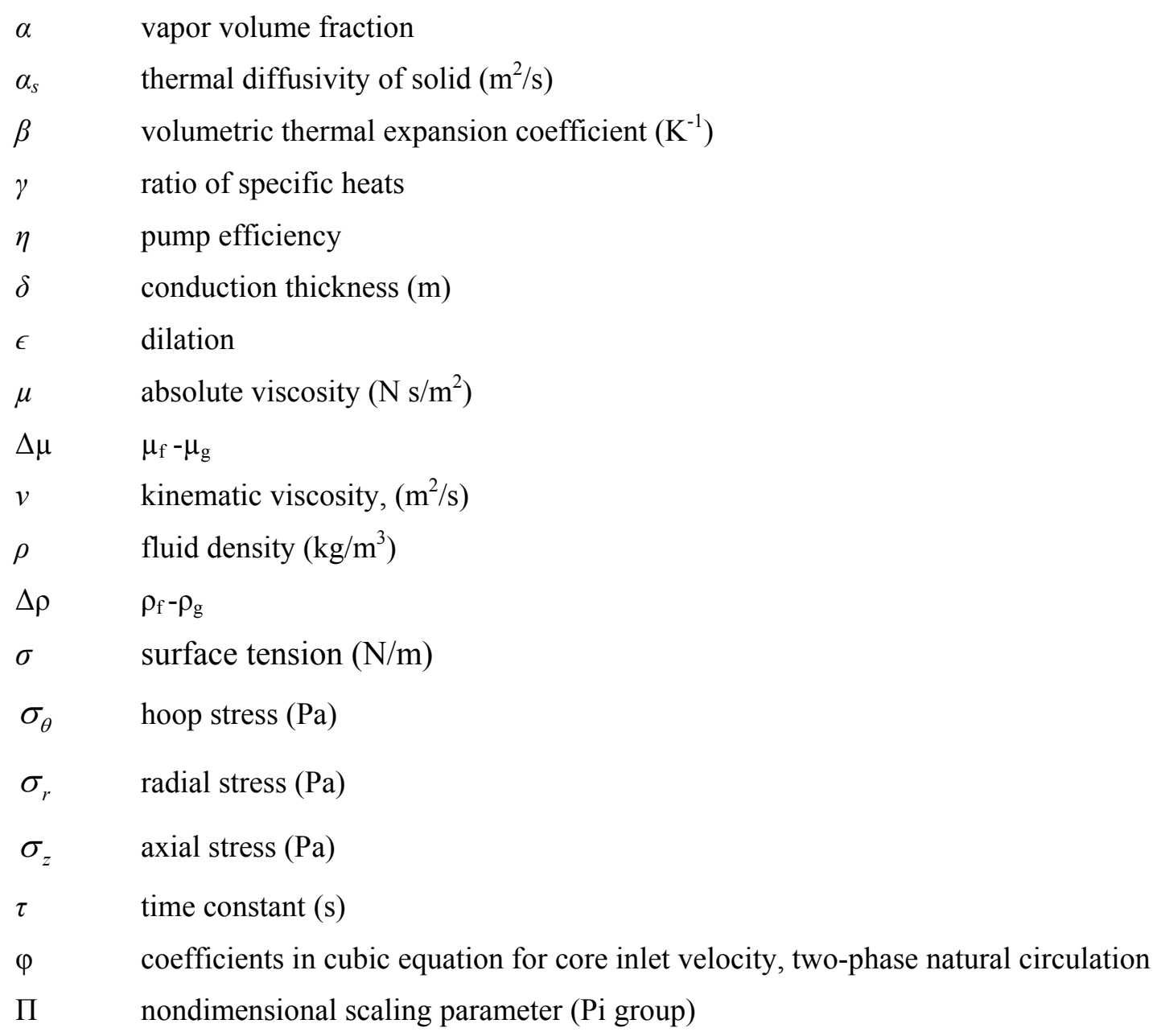




\section{$\underline{\text { Subscripts }}$}

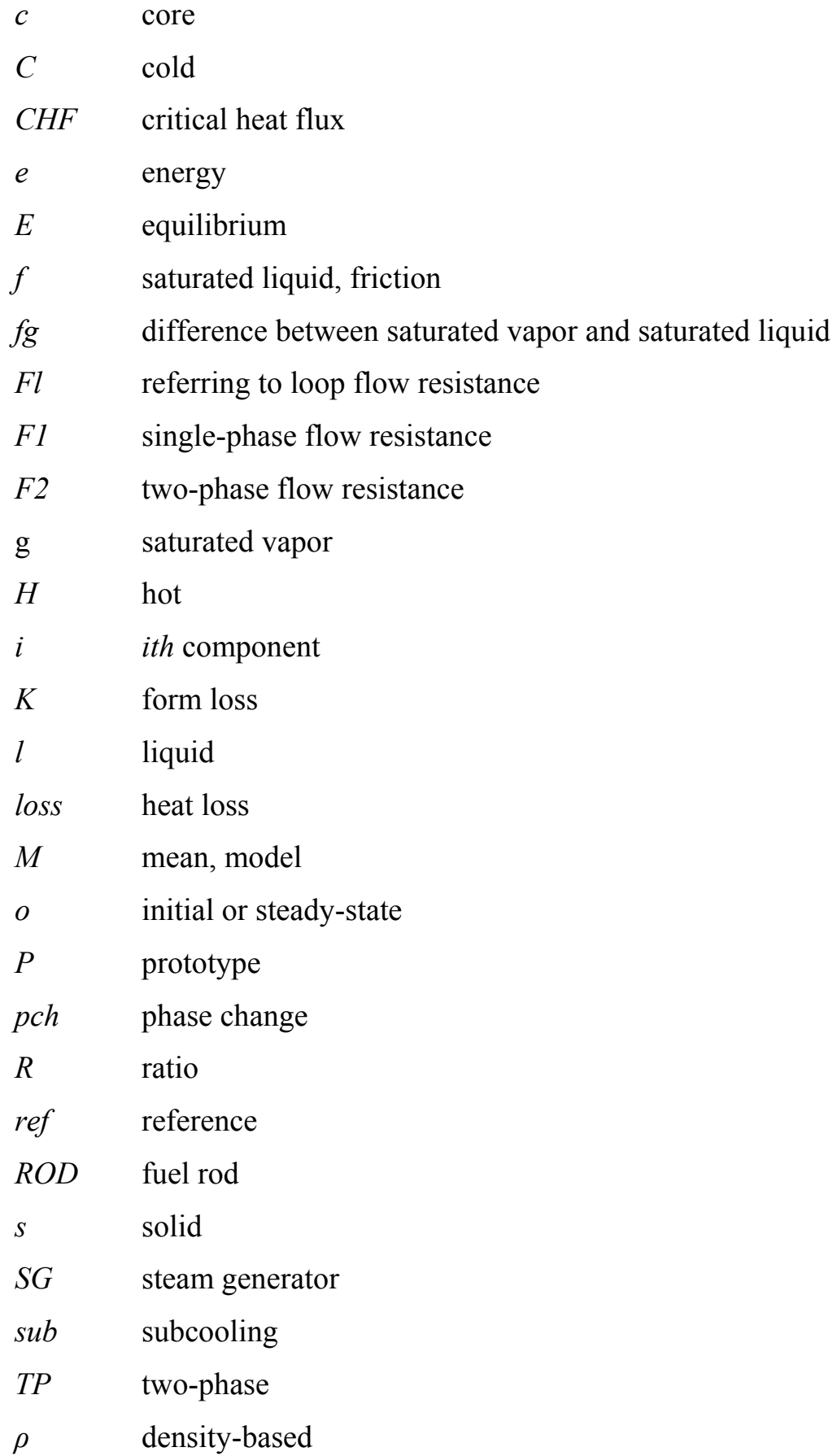

$\begin{array}{ll}m & \text { model } \\ p & \text { prototype } \\ + & \text { normalized with respect to initial break conditions }\end{array}$




\section{Scaling Analysis Techniques to Establish Experimental Infrastructure for Component, Subsystem, and Integrated System Testing}

\section{INTRODUCTION}

The growing demand for energy, coupled with environmental concerns, has resulted in an increased interest in alternative energy sources. Nuclear hybrid energy systems (NHES) that incorporate renewable energy sources, such as solar or wind energy, combined with a nuclear reactor (i.e., small modular reactor) and energy storage are currently under consideration. Recognizing the variability in renewable energy resources, integration of nuclear energy with renewable sources could provide reliable, baseload energy to meet the peak electricity demand imposed on the grid. Excess energy, produced either during times of low demand or high renewable availability, could be diverted to alternate output streams, such as providing process heat for potential industrial or chemical applications. NHES potentially could satisfy various energy demands (electrical and thermal) while providing system reliability, robustness, and resilience. Figure 1 provides a schematic of an example NHES system with various interconnections and coupling (Bragg-Sitton et al. 2013). In addition to mitigating the variability of renewable energy sources, NHES provides opportunities to produce revenue from different product streams and avoids capital inefficiencies by matching electrical output to demand by using excess generation capacity for other purposes when it is available. NHES also provides the opportunity and flexibility to enhance revenue collection based on the profitability between power production and industrial application (Ruth et al. 2014).

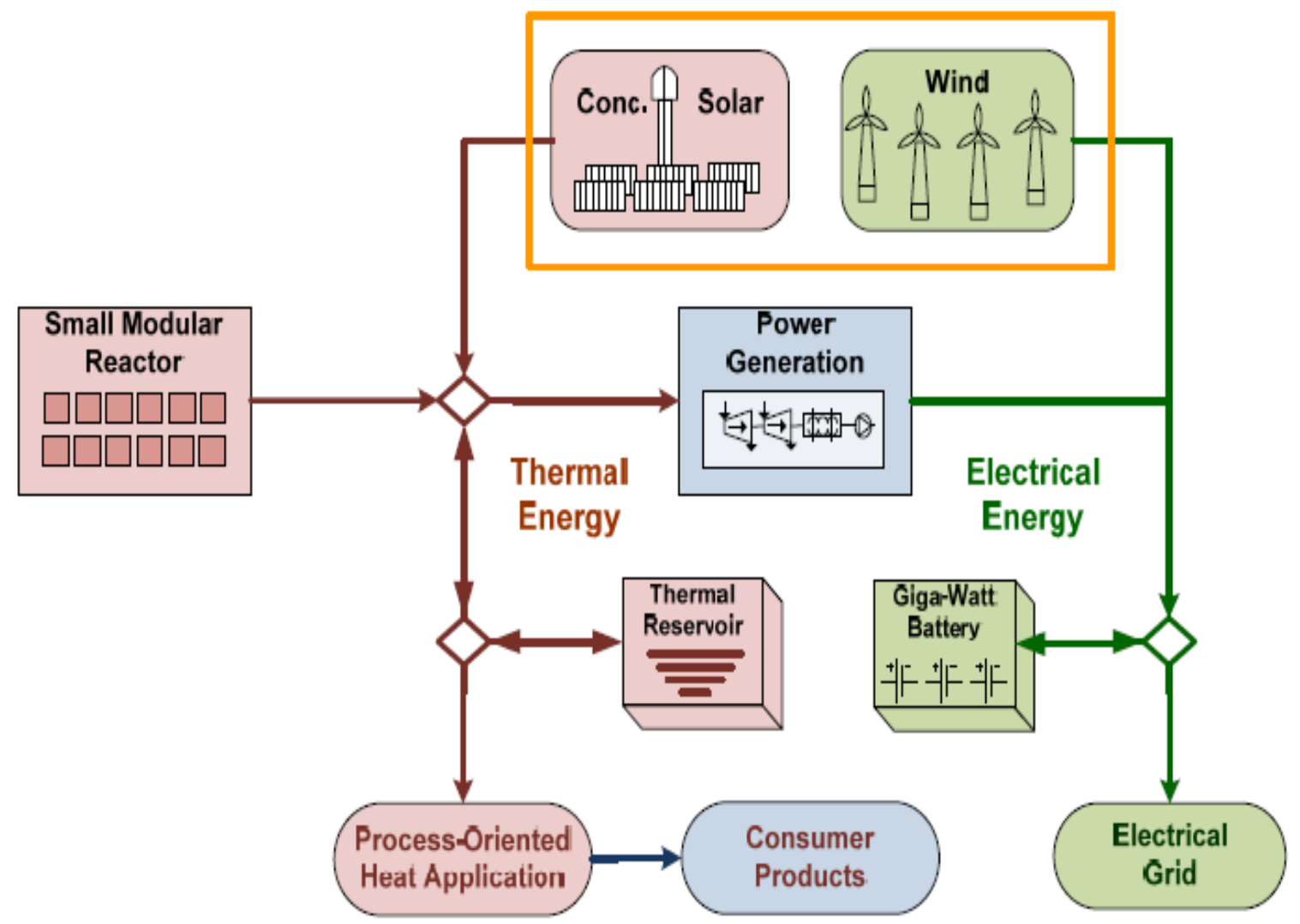

Figure 1. Generalized Nuclear hybrid energy system architecture (Bragg-Sitton et al. 2014) 
The main objective of NHES is to support and develop technologies to achieve safe, economic, competitive energy products, (i.e., electricity and hydrogen), along with other possible industrial products (i.e., synthetic fuel production) in a sustainable carbon-free manner. A leading application considered for hybrid systems is the use of nuclear process heat and electricity for efficient hydrogen and oxygen production via high temperature steam electrolysis. This hydrogen and oxygen product can then be used to support synthetic transportation fuel production and other vital chemical products and commodities. Hydrogen can also be used as an effective energy storage medium. Nuclear energy integrated into advanced hybrid systems opens several intriguing opportunities to advance energy security.

The NHES program has initiated preparation of the integrated technology development roadmap, which combines several levels of research and development, analysis, design, and testing using the critical technologies required to support economic, reliable, and safe operation of the NHES. The technology development roadmap process emphasizes testing to validate the understanding and viability of each advanced technology at every phase of its advancement (Collins 2009).

This research, development, and demonstration program is necessary to prove the viability of critical NHES technologies at full or near full scale (scaled system) prior to deployment to enable better understanding of integrated system behavior at prototypic conditions. Integrated large-scale test capabilities are therefore an important and necessary resource in the development of advanced energy technologies and hybrid energy systems. An essential step in the commercialization of advanced nuclear reactor technology is scaled testing to demonstrate integrated dynamic performance of advanced systems and components when risks cannot be mitigated adequately by analysis or simulation, and further testing in a prototypic environment is needed for validation and higher confidence (Larson et al. 2007). A widely accessible scaled component testing capability is being developed at the Idaho National Laboratory (INL). Due to its relevance to advanced reactor technologies, this new high-temperature multi-fluid, multi-loop test facility will be called the Advanced Reactor Technology Integral System Test (ARTIST) facility (O'Brien et al. 2014). This thermal hydraulic test facility can be integrated with co-located systems to enable characterization of coupled systems in the prototypic environment. Design, fabrication, assembly, and operation of the high-temperature flow and heat transfer loops and thermal energy storage systems are currently being supported by INL laboratory-directed research and development (LDRD) funding.

The ARTIST facility is intended to support the development of advanced technologies and is adaptable to varying interface and support requirements because, by definition, the advanced technologies will not be at a stage of technology readiness or design development where specific and rigid test capabilities can be defined. Therefore, the system is designed with the flexible inherent feature to support various possible coupled hybrid systems along with other potential advanced technology, advanced reactor, and small modular reactor programs.

This report discusses detailed scaling (component and integrated system) and provides details on heat transfer figures of merit that will assist with establishment of experimental infrastructure for component, subsystem, and integrated system testing to advance the technology readiness of components and systems to the level required for commercial application and demonstration (Reyes 2005, Reyes and Hochreiter 1998, Zuber 1991).

The objectives of the scaling analysis of NHES are threefold:

1. Obtain the physically-scaled dimension for the model based on the prototype of interest

2. Predict and simulate relevant thermal hydraulic flow and heat transfer behavior at the component and system levels depending on the test matrix/phenomena of interest

3. Obtain key thermal hydraulic data for validation of thermal hydraulic safety analysis computer codes. 
General test matrix objectives for NHES are as follows:

1. Enhance confidence and confirmation of the thermal hydraulic and dynamic performance at scale to validate models

2. Demonstrate the mechanical performance and coupled system interfaces under normal and transient operating conditions at scale

3. Demonstrate advanced instrumentation performance and viability of coupled systems

4. Demonstrate operation of coupled hybrid systems with required control and production of energy products/commodities (e.g. power production and hydrogen production [using high temperature steam electrolysis], reverse osmosis for desalination)

5. Verification and validation of methods/codes and models to support NHES technology

6. Assess dynamic response of integrated components and systems at subscale level prior to full-scale demonstration

7. Develop and demonstrate startup and in-service inspections along with test procedures that will be vital for testing at full scale or commercial level

8. Understand the design development needs and challenges that still exist in the particular system (addressing at a lower scale the risk of incompatible interfaces in a coupled system).

This report supports the development of advanced nuclear reactor technology and NHES and their coupled adaptation to commercial industrial applications that potentially will advance U.S. energy security, economy, reliability, and reduce carbon emissions. The needs for testing and feasibility studies of the coupled systems by promoting experimental infrastructure development can also support other projects because of similar developmental needs and the data required for validation of models in thermal energy storage and transport, energy, and conversion process development. 


\section{OVERVIEW OF THE SYSTEM INTEGRATION LABORATORY (TEST FACILITY)}

A primary function of the INL Systems Integration Laboratory (SIL), located within the Energy Systems Laboratory (ESL) building, is to integrate energy systems using innovative approaches and disparate energy system component testing. This research leverages hybrid energy concepts and complementary characteristics of different energy sources - such as renewable, conventional and unconventional fossil, and nuclear sources - to gain efficiencies through advanced integrated system controls and engineering technologies that improve environmental and energy performance for a given system or process. Experimental research on hybrid approaches in this laboratory may be used to significantly expand the application for new nuclear reactor technology beyond electricity.

A significant purpose of this research is to reduce both technical and economic risks associated with future energy systems. This laboratory will provide configuration-flexible facilities to conduct experimental laboratory, bench-, pilot-, and engineering-scale research and testing necessary to demonstrate commercial readiness of integrated energy systems. The laboratory will provide dedicated test platforms to demonstrate the specifications necessary to carry hybrid energy system concepts through the appropriate levels of technology readiness required for commercialization.

Experiments in this facility will acquire performance data, identify scalability issues, quantify technology gaps and needs for various hybrid or other energy systems. The facility experiments will provide infrastructure to develop solutions in each of the five energy-related platforms:

- Resource extraction and feedstock processing

- Heat transfer/energy integration

- Product synthesis and energy storage

- Byproduct capture and management

- Process monitoring, diagnostics, and control.

The SIL provides 16,000 square-feet of large high bay and exterior yard space to develop and demonstrate energy systems integration using innovative approaches and disparate energy system component testing. This section provides an overview of the test facility layout, potential integration studies, and testing of hybrid energy systems (see Figure 2).

INL is initially focusing on research and development with the following SIL offerings:

1. Energy systems integration, modeling and simulation, optimization, and instrumentation and control capabilities

2. Robust thermal hydraulic energy delivery and advanced power cycles that respond to grid demand and enable increasing renewables, transformational utility-scale energy storage options, and micropower closed energy systems testing

3. Energy storage in electrical, mechanical, thermal, and chemical energy with a focus on electric vehicle charging and clean hydrogen and oxygen feedstock production

4. Dynamic fuel cell operations for short timescale grid power management

5. Dynamic utilization of low grade heat in industrial processes

6. Water energy nexus solutions, including advanced cooling cycles, and desalination concepts. 


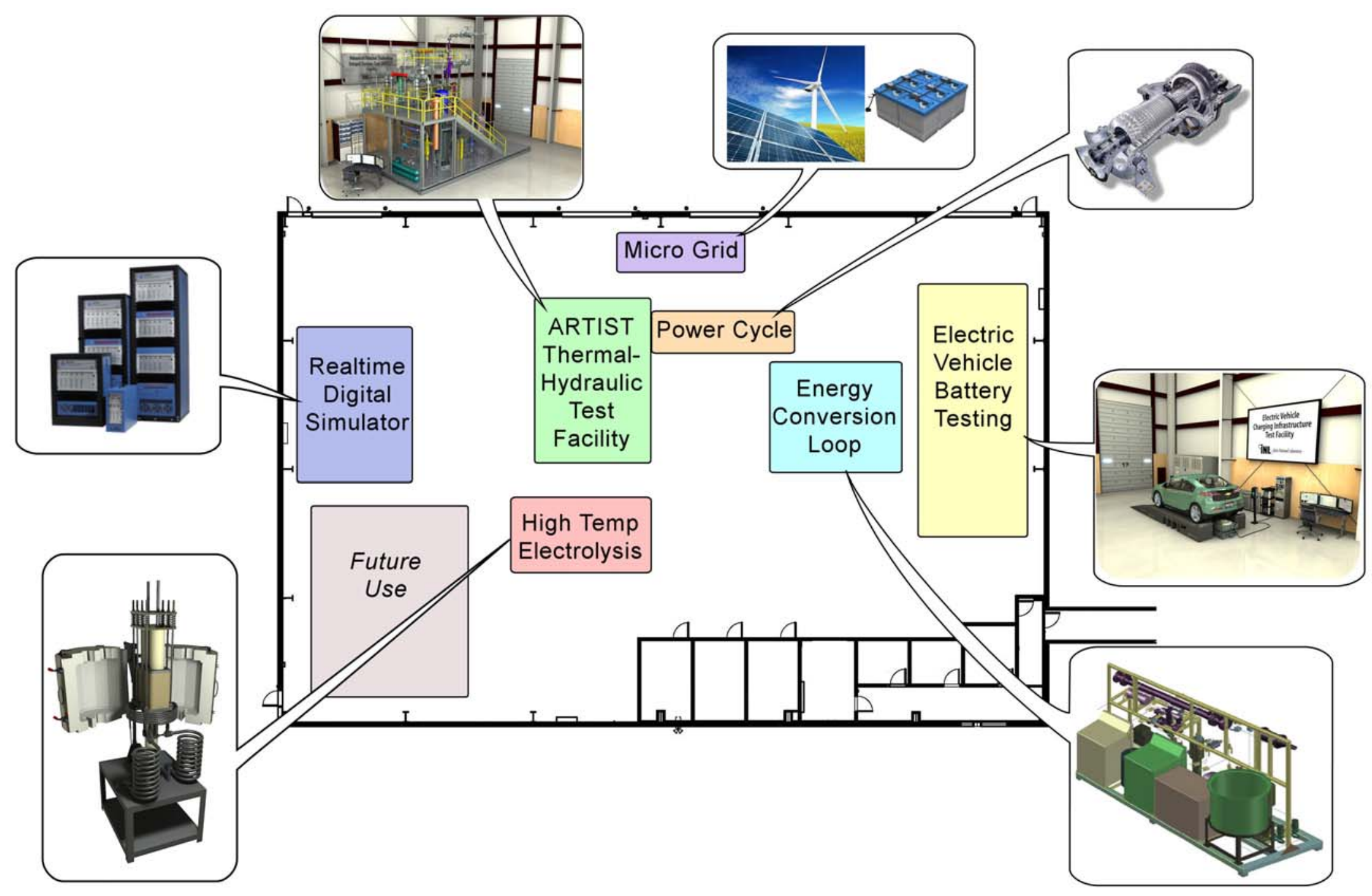

Figure 2. Energy Systems Laboratory preliminary highbay design layout. 
Five projects are currently under construction in the INL SIL or have been conceptually designed:

1. ARTIST- Multi-Fluid, Multi-Loop Thermal Hydraulic Test Station (a flexible thermal energy circulation and delivery test station); conceptual design completed with LDRD funding in FY 2014.

2. Energy Conversion Loop (an industrial energy load simulation and test skid); conceptual design and skid construction partially completed in FY 2014 under Department of Energy (DOE) Nuclear Energy University Program funding.

3. Grid Integration Co-Simulation and Testing (real-time digital simulator of electricity user applications, energy storage, and grid elements); conceptual design completed with LDRD funding in FY 2014.

4. Microgrid/Smartgrid Testbed (mainly a wind and solar energy microgrid); conceptual design and equipment installations completed with LDRD funding in FY 2014; commercial equipment donations also received in FY 2014.

5. Electrical Vehicle Battery Indirect Charging Test Station; test unit design and installation completed in FY 2014 under DOE Transportation Vehicle program funding. 


\section{SYSTEM INTEGRATION LABORATORY FACILITIES AND RESEARCH ACTIVITIES}

\subsection{Multi-Fluid, Multi-Loop Thermal Hydraulic Test Facility 3.1.1 Purpose}

A multi-fluid, multi-loop thermal hydraulic test facility is currently being designed for installation in the SIL. The Advanced Reactor Technology Integral System Test (ARTIST) Facility is a nonnuclear, electrically heated facility that will be used to test thermal hydraulic behavior for multiple fluids related to advanced reactor concepts. For more information on the facility, the reader is encouraged to refer (O’Brien et al. 2014).

\subsubsection{Description}

A process flow diagram for the multi-fluid, multi-loop thermal hydraulic test facility is illustrated in Figure 3. The facility includes three thermally interacting flow loops: helium, liquid salt, and steam/water. The helium loop design flow rate is up to $525 \mathrm{LPM}$ at $7 \mathrm{MPa}$ and a loop pressure drop of $100 \mathrm{kPa}$. The high temperature portion of the flow loop is designed to handle helium temperatures up to $800^{\circ} \mathrm{C}$. The nominal power requirement for the high-temperature gas heater is $60 \mathrm{~kW}$. The helium loop will include a high-temperature test section for heat transfer and materials studies.

The center part of Figure 3 shows the liquid salt portion of the multi-loop facility. The loop will provide flow rates up to $20 \mathrm{LPM}$. The entire liquid salt flow loop will be heat-traced to prevent salt from freezing and causing a flow blockage. The maximum salt temperature will be $\sim 480^{\circ} \mathrm{C}$ as it flows through the intermediate heat exchanger (IHX) and heat is transferred from the helium loop to the salt loop. For independent operation of the liquid salt loop, an IHX bypass will enable salt flow directly to the high temperature test. An auxiliary heater will be designed to independently heat the salt to the maximum operating temperature of $480^{\circ} \mathrm{C}$ even when the IHX is bypassed. Its nominal design heater power will be $75 \mathrm{~kW}$.

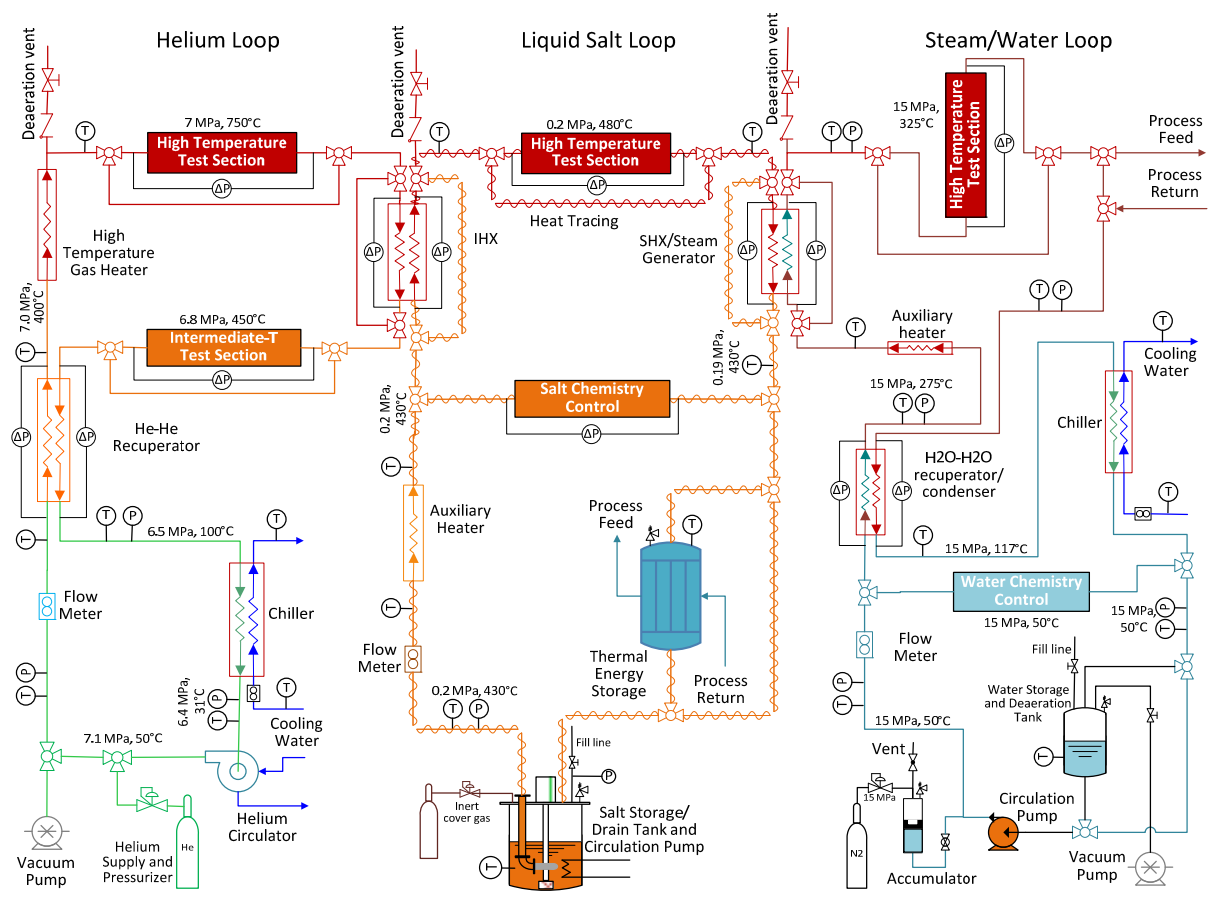

Figure 3. Schematic of the proposed multi-fluid, multi-loop thermal hydraulic facility. 
The right side of Figure 3 shows the steam/water tertiary loop. The secondary heat exchanger (SHX) can serve as a steam generator or simply a single-phase heat exchanger, depending on the conditions to be simulated in the tertiary loop. For most tests, the conditions in the tertiary loop will be intended to simulate conditions in the primary loop of a pressurized water reactor (PWR). PWR conditions will be needed for materials/ corrosion studies of accident-tolerant fuels, new cladding materials, CRUD formation, etc. Alternately, at lower operating pressure, the tertiary loop can simulate the secondary side of a PWR system with steam generation for process integration studies. Flow through the hot water loop will be produced by a pump designed to operate at $15 \mathrm{MPa}$ with a nominal water flow rate of 5.7 LPM. The maximum temperature is $325^{\circ} \mathrm{C}$ within the loop water. For cases where the SHX is not present or is bypassed, an auxiliary heater will be used to achieve the desired $325^{\circ} \mathrm{C}$ test section inlet temperature (O’Brien 2014).

\subsection{Energy Conversion Loop}

\subsubsection{Purpose}

Advanced nuclear reactor concepts that operate at higher temperatures than the current fleet of light water reactors are well suited for the cogeneration of process heat and electricity. These plants can offer high, medium, and/or lower grade thermal energy for many other industrial needs. Beyond generating electricity, these systems will have advanced energy conversion known as intelligent (process) control systems (ICS) and energy products as the foremost process heat. An energy conversion loop (ECL) is under development to demonstrate an ICS-based, multi-component energy conversion system. The ICS will demonstrate rudiments of advanced instrumentation and control, such that it will facilitate understanding of non-linear, real component behavior, scaling and importance of virtual testing via an adaptive, trained ICS. The project will consider extrapolation of results to balance-of-plant metrics under normal and off-normal events. The overall objective of this project is to directly address the loadfollowing capabilities of a $10 \mathrm{~kW}$ to $30 \mathrm{~kW}$ scale ECL via design, deployment, and demonstration. This research is a Nuclear Energy University Program project led by the University of Idaho with assistance from the INL.

\subsubsection{Description}

The ECL has the potential to reach $650^{\circ} \mathrm{C}$, which is sufficient for many relevant HTR applications; for example: fuels drying, desalination, biomass pyrolysis, oil shale/tar sands and petroleum refining. The initial heat transfer medium will be air. The ECL ICS will feature software-based models and simulation capability and will thus be amenable to validation and verification. Application of heuristic methods (i.e., artificial neural networks), as part of the ICS enable us to characterize components and the ECL, and provide intelligent instrumentation and control. The project will investigate the following: (a) dynamic simulation and control of reactor-driven (simulated high temperature gas circulator) process heat application 'modules', including interactions of multiple thermal and electrical loads, and (b) simulation and analyses for the use of (interactive) instrumentation and control, data acquisition, prognostics, and diagnostics or ICS (e.g., adaptive controllers, "fuzzy logic", artificial neural networks, genetic algorithms and related to handle combined interactions between the heat source, heat transport, energy conversion, and thermal and electrical loads).

As shown in Figure 4, the ECL has three loops and one flow-through line. The streams are color coded to show relative temperature in the line; thin lines represent the air loop whereas the bold lines represent the water loop. The three different colored backgrounds show the distinction between the three subloops tested. The primary loop is a heated air loop that passes through the high-temperature gas circulator and heats the air to $218^{\circ} \mathrm{C}\left(425^{\circ} \mathrm{F}\right)$. The high temperature air loop has a nominal pressure of 100 psi. The hot air exchanges heat with cold water to produce steam within a steam generator embedded within the boiling water/steam loop. The steam passes through a turbocharger which provides compression to the hot air loop. After expanding within the turbocharger, the steam is condensed to water 
within a chiller. The water is then pumped back to the steam generator. The hot air leaving the steam generator can be used to melt wax in a thermal storage tank. This wax acts as a thermal capacitor to store heat when it is not needed by the heat load or to provide heat to the heat load when the high temperature gas heater is not operating. After the thermal storage unit, the hot air provides heat to water via two heat exchangers. The hot water is stored in a standard home water heater. The water is used in a washing machine, which is part of the heat load for this system. The ejected water from the washer is further cooled in the chiller and is pumped back to the air/hot water heat exchangers to complete the cycle. The warm air exiting the hot water heat exchangers is then used to heat ambient air, which is used in a clothes dryer. The air is exhausted from the dryer to the atmosphere. The cool air within the high-temperature air loop is recompressed within the turbocharger before being reheated within the high temperature gas heater (Ostrom 2015).

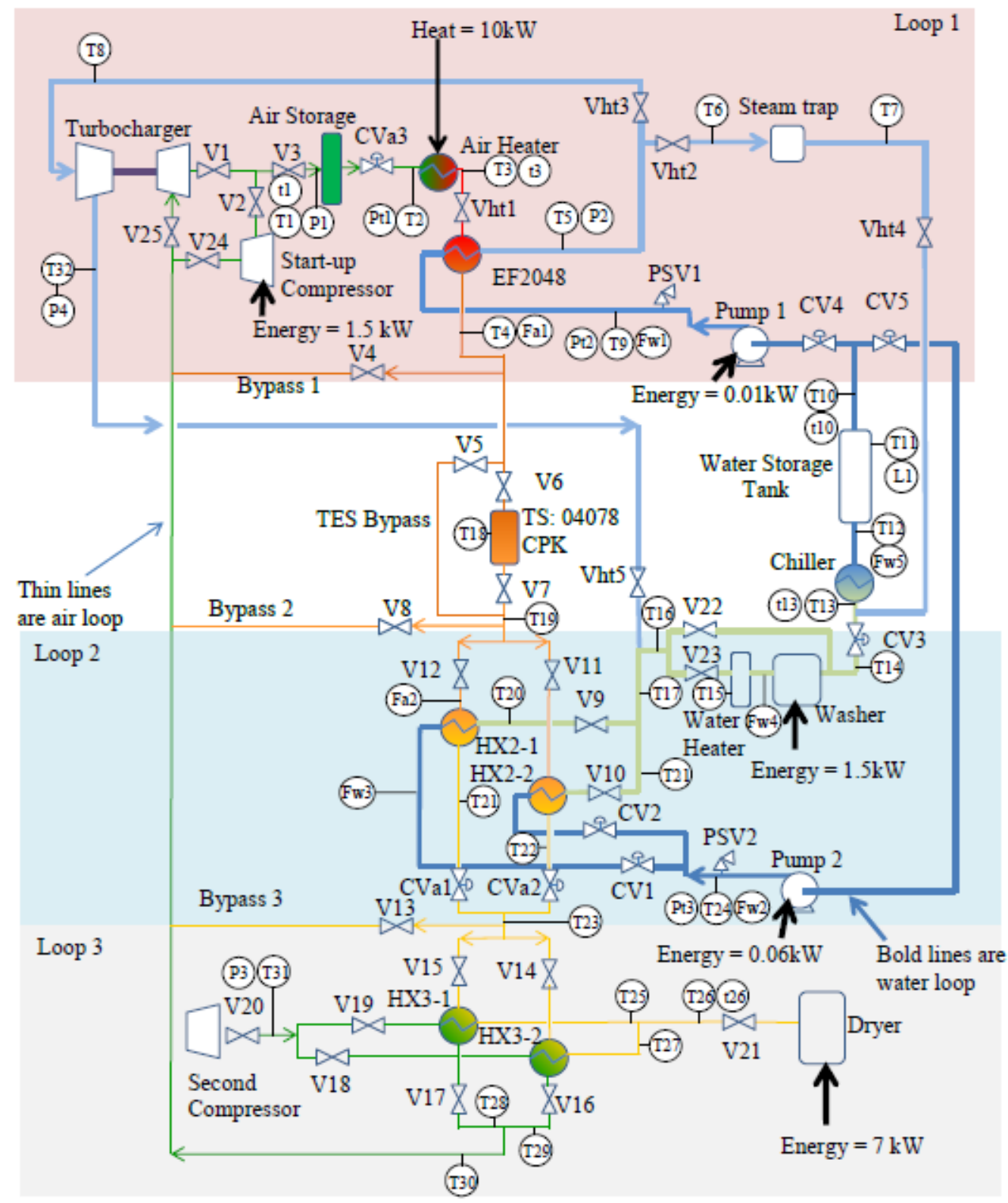

Figure 4. The energy conversion loop for the Phase I configuration . 


\subsection{Grid Integration Co-Simulation and Testing}

\subsubsection{Purpose}

Real-time simulation (RTS) has found applications in numerous areas of power and energy systems research. These areas include testing protection schemes, testing control schemes, transient analysis, bulk interconnection and feasibility studies, etc. Advantages of real-time simulations in power systems are well established in the literature based on experiences in the industry, research, and academia. Since the advent of real time environments, simulations were based on centralized processor/s (simulators such as RealTime Digital Simulator $\left[\right.$ RTDS $^{\circledR}$ ], Opal RT, etc.), and the equipment to be tested (hardware/software) was connected and characterized by a bidirectional energy flow. Such simulations gauge the performance of the equipment in the desired aspects when connected to the networks modeled within the real time simulators. The outcome of real time simulations resembles the performance of the equipment in a practical power system and has proven reliable.

\subsubsection{Description}

Energy Systems Laboratory (ESL-SIL) at INL is currently developing RTS capabilities for performing advanced assessment of energy systems, as shown in Figure 5. ESL has commissioned two RTDS $^{\circledR}$ racks that have been specially configured to perform simulations such as controller-hardware-in-the-loop and power-hardware-in-the-loop. Researchers at ESL have also developed a dynamic microgrid model of the widely accepted Consortium for Electric Reliability Technology Solutions (CERTS) in the RTDS ${ }^{\circledR}$. Physical devices (such as distributed energy resources small wind turbines, photovoltaic panels, etc.) can be connected with the CERTS microgrid model and, hence, perform power-hardware-in-the-loop testing. This model is under further development so as to have additional features and capabilities to provide wider functionalities of renewable and distributed energy assimilation (Panwar 2015, Muljadi 2015).

Future projects expected to use the $\operatorname{RTDS}^{\circledR}$ capabilities are:

- Dynamic Simulations for Large Scale Electric Power Networks in a Real Time Environment Using Multiple RTDS $^{\circledR}$ : The proposed research will link two spatially distributed RTDS $^{\circledR}$ (INL and the National Renewable Energy Laboratory) to perform a synchronized real time simulation using Energy Sciences Network. Dynamic analysis and co-simulations in Institute of Electrical and Electronics Engineers test systems and reduced order interconnection level networks will be performed. A generalized approach for performing distributed real-time simulation will be developed and implemented with academic and research labs that have RTDS $^{\circledR}$ technology. The objective of this project is to leverage DOE national laboratory assets (hardware installations) and capabilities (personnel and modeling efforts) to pursue analysis via high fidelity real-time simulation.

- Real-Time Assessment of the Dynamics between Utility-Scale Energy Storage Devices and Power Grids: This project is concerned with testing of utility-scale energy storage devices, such as batteries used in electric vehicles and fuel cell-electrolyzers and its interaction with power grids in a RTS. Specifically, one project is concerned with the dynamic and transient analysis of the performance of electric vehicles, including vehicle-to-grid capability of the battery, and its effect on the power system. Another project being pursued is related to the use of characterized electrolyzer data and assessing electrolyzer interactions with the power grid for stability and power quality correctional attributes. The RTDS will primarily simulate the ancillary power system, which can be a microgrid, or an Institute of Electrical and Electronics Engineers standard test system. The RTDS will also function as a data acquisition and control unit. It will acquire data from the device under the test, and control the interfaces to the device under test. These interfaces include a power amplifier and a power converter. 


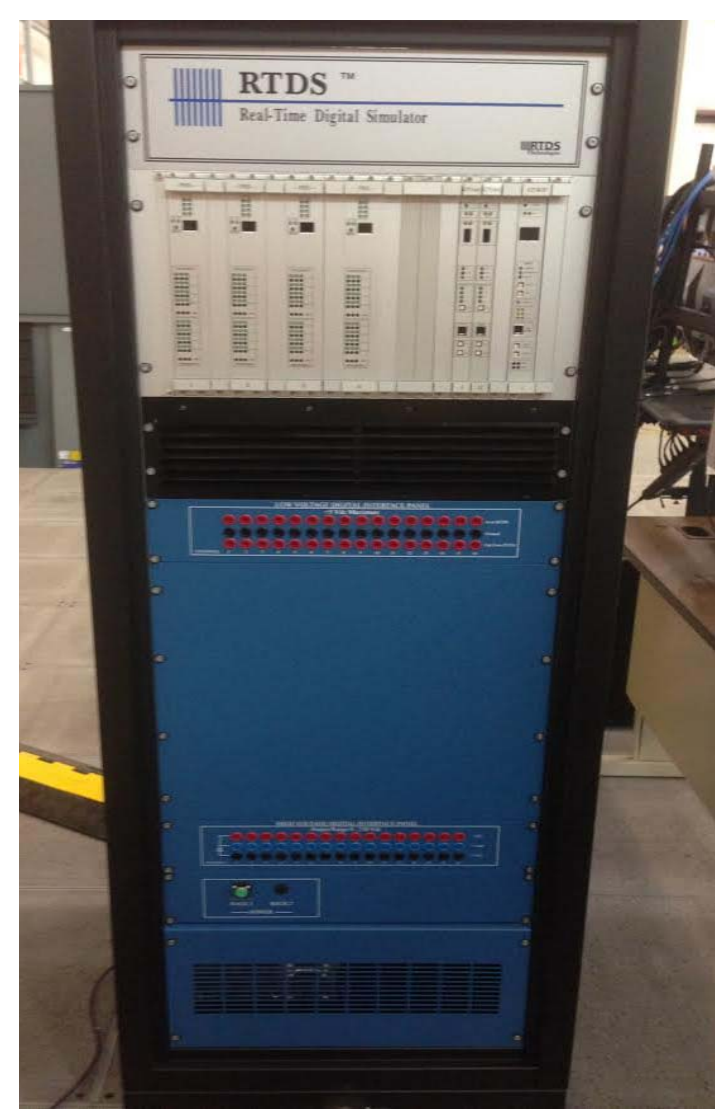

Figure 5. Picture of a single RTDS® rack.

\subsection{Microgrid/Smartgrid Testbed}

\subsubsection{Purpose}

With increasing demand for renewable integration, the requirements on the legacy grid will rapidly exceed current capabilities. The ability to understand and model the system dynamics of real-world microgrids and distributed energy resources at multiple scales and geographic locations is essential to successfully increasing renewable penetration. The developing micro/smartgrid platform at INL addresses this issue through the development of distributed energy resources grid testing and modeling capabilities in an integrated collaborative environment. In order to achieve this goal, INL will design and construct an open-source smartgrid platform with integrated control system and component interaction research and development (as shown in Figure 6), develop scalable grid models from acquired data and work with industry to begin hardware and software integration testing for future microgrid and distributed energy resources applications.

\subsubsection{Description}

INL operates an inverter-based microgrid for research on high-penetration renewable power integration. Key components include $>13 \mathrm{~kW}$ of photovoltaic (expanded to $>30 \mathrm{~kW}$ ) in various arrays and interconnection technologies from microinverters to off/on-grid inverters. The off-grid capable photovoltaic array is paired with a $1568 \mathrm{Ah} / 24 \mathrm{VDC}$ lead-acid battery (flooded lead acid). Two $2.4 \mathrm{~kW}$ wind turbines are also part of the grid, with expansion plans for a $50 \mathrm{~kW}$ turbine and addition of several concentrated solar power Stirling dish/generator systems. Additional energy storage devices within the distribution grid include: a $10 \mathrm{~kW} / 18 \mathrm{kWh}$ Enerdel secondary-use Li-ion vehicle battery, and a 100 kW/80 kWh secondary-use Li-ion battery with Princeton Power GTIB-100 kW inverter system. 


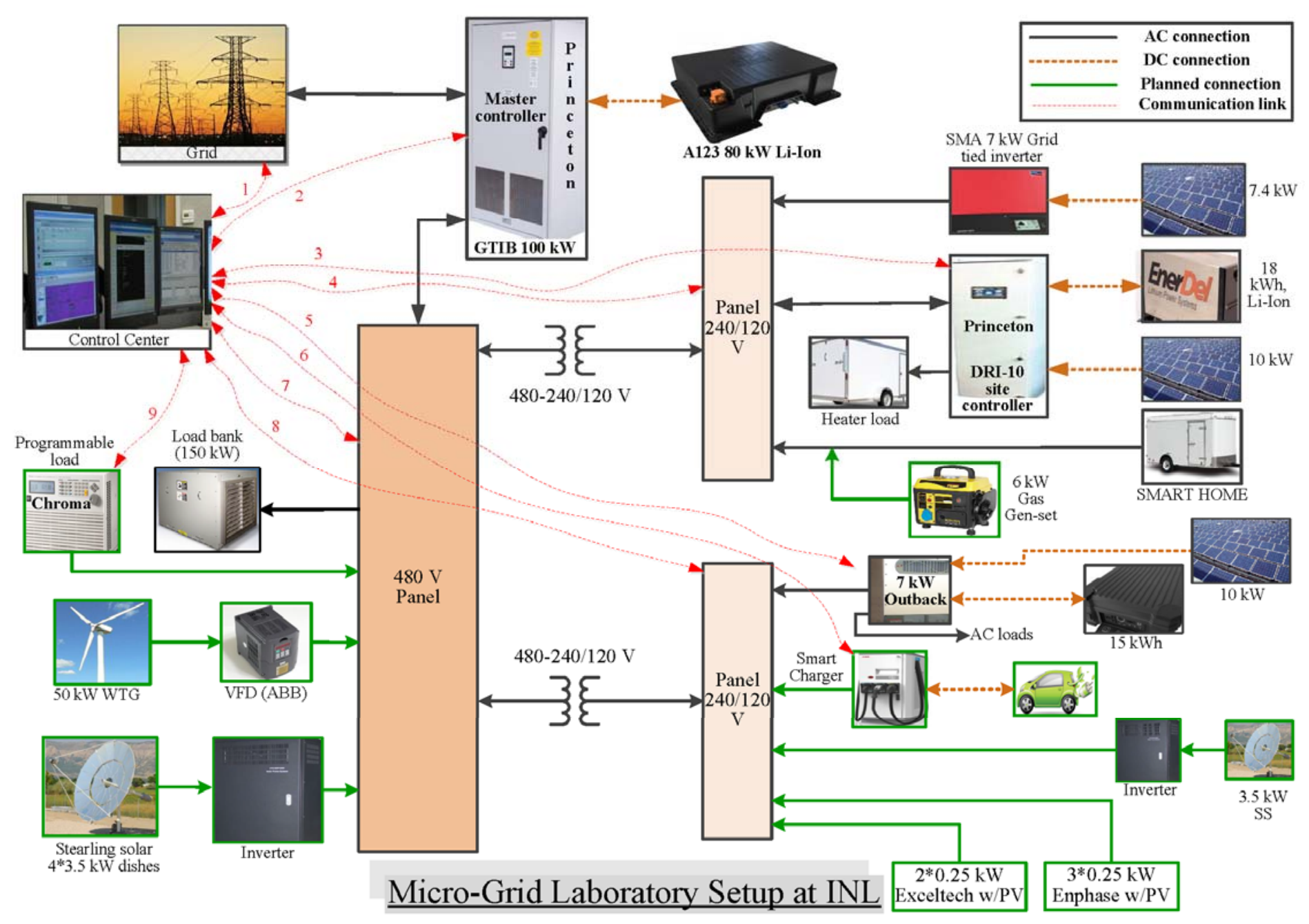

Figure 6. Microgrid platform with integrated control system. 
The microgrid is regulated using a Princeton Power microgrid site controller that can also provide onboard battery management system capabilities. Thermal building systems (heating and cooling) are to be utilized for demand management applications, including an ice/chilled storage A/C system to provide peak shifting capabilities. For prolonged operation during unfavorable renewable energy availability, INL has also planned for the addition of fueled electric generation equipment (diesel, microturbine, Stirling, and/or fuel cell), combined heat and power, and fuel access/storage systems. The INL microgrid, while providing customer loads, can be reconfigured as needed by temporarily re-routing power from other sources for some or all customers.

A Stirling genset with multi-fuel capabilities, coupled with the proper grid interface inverter (both on/off grid capable, with synchronizing, droop mode available, etc.), will allow for multiple research, development and demonstration paths to occur at INL in conjunction with other activities such as biofuels development, grid integration, smart grid modeling and application, hybrid energy systems, etc.

Internal and external development and work/permit control processes have been achieved to enable installation and inspection of the first phases of equipment. Currently in place are $12 \mathrm{~kW}$ of solar photovoltaic, five microinverters, one grid-tie string inverter, one on-off grid inverter/battery system, two smart inverters/four-quadrant power converters, multiple electrical distribution panels, cabling and transformers, two secondary-use Li-ion battery systems, multiple metering systems, initial control and communication layers, and several controllable load connections and systems in place or in final development stages.

The project also has concentrated solar power and some wind turbine equipment on-site and has a net-metering agreement in place with Idaho Falls Power to enable both grid-tie smartgrid interaction and island/microgrid mode research. The project has the initial RTDS rack installed and associated equipment installation and modeling has been initiated to enable HIL testing and associated research in coordination with other researchers. Coordination is also in place to connect the Nuclear Energy University Program industrial load/thermal loop research into the microgrid (Bhattarai 2015).

\subsection{Electrical Vehicle Battery Indirect Charging Test Station}

\subsubsection{Purpose}

The INL Vehicle Systems group has extensive experience with testing and analysis of advanced technology vehicles through the support of the DOE Advanced Vehicle Testing Activity. With the emergence of plug-in vehicle technologies, INL has developed the capabilities to test advanced charging infrastructure technology to understand and benchmark the state of the art technology with a focus on system efficiency, electromagnetic field strength, power quality, cyber security vulnerabilities, and test procedure development to support industry standards. Recently, the wireless power transfer (i.e., wireless charging) testing capability at INL was named as a DOE core laboratory capability. INL is focused on solidifying its role as DOE's premier test facility for all electrified vehicle charging infrastructure testing activities as related to energy efficiency. Figure 7 shows a photo of the Electric Vehicle Charging Infrastructure Testing Facility within SIL during the evaluation of a wireless charging system installed on a Chevrolet Volt.

\subsubsection{Description}

The Charging Infrastructure Test Facility is capable of testing a wide range of advanced charging systems intended for light and medium duty electrified vehicles. Testing can be performed in conjunction with a vehicle or as a stand-alone charging subsystem. With a wide range of power capability, high precision measurement equipment, and sophisticated testing software, this test facility is capable of completing large multi-dimension test matrices via automated testing. The facility is also highly flexible, allowing for quick reconfiguration to respond to new technology testing needs (Carlson and Normann 
2014, INL 2013). A high level list of the Charging Infrastructure Test Facility capabilities and testing activity is as follows:

- Power capabilities (L1, L2, and direct current fast charger [DCFC])

- $\quad$ Up to $9 \mathrm{~kW}$ AC off-board a vehicle

- $\quad$ Up to $58 \mathrm{~kW}$ DC off-board a vehicle

- Vehicle charging test (within power limits of vehicle up to 480VAC 100 amp service)

- Vehicle testing capabilities

- Wireless power transfer coil positioning (automated via LabVIEW servo-motor control) under vehicle

- Controller area network communication

- Subsystem (off-board the vehicle) testing capabilities

- Fiberglass test fixture to hold vehicle-side coil above wireless power transfer coil positioning (automated via LabVIEW servo-motor control)

- J1772 emulation module

- Programmable AC and DC load banks (to emulate vehicle electrical power consumption)

- Data acquisition

- LabVIEW host control system to orchestrate test sequencing and data acquisition

- Hioki power meters to measure power, energy, power quality, and harmonics

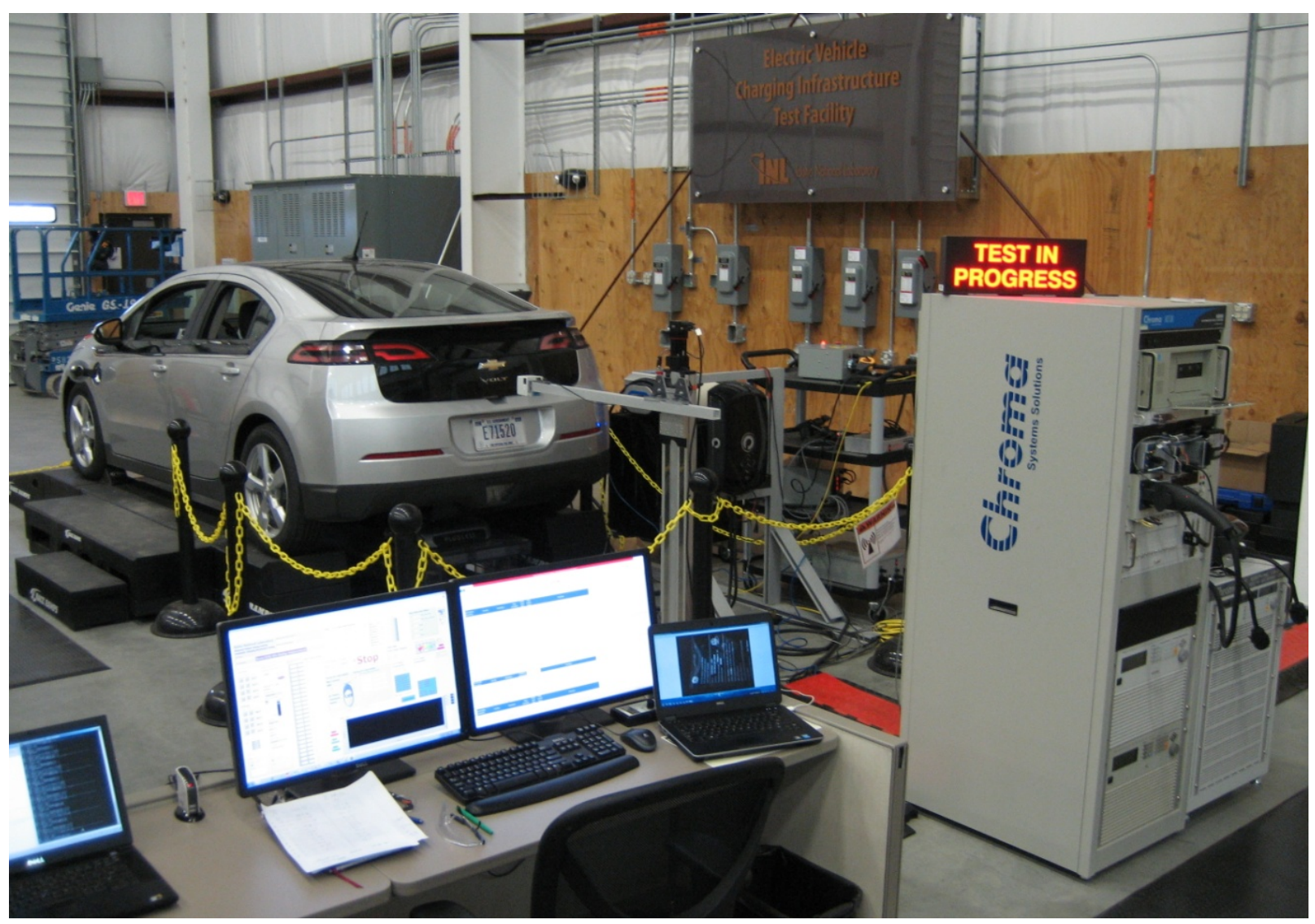

Figure 7. Electric Vehicle Charging Infrastructure Testing Facility. 
- NARDA electro-magnetic field meter 2-axis automated positioning system $(1.0 \mathrm{~m} \times 1.0 \mathrm{~m})$

- $\quad$ FLIR Infrared camera

- Ambient temperature impacts on charging

- $\quad 0^{\circ} \mathrm{C}$ to $50^{\circ} \mathrm{C}$ impacts on Level 1 and 2, and DC fast charging times and profiles, and battery acceptance rates

- Field operations charge profiles and driver preferences

- $\quad$ Large history of managing large volumes of real world charging profiles and statistics during 124 million miles of plug-in vehicle miles and 6 million charge events

- INL Cyber Security Vulnerability Assessment Team

- Cyber vulnerability assessment of vehicle and charging infrastructure controls systems, communications, and interconnectivity. 


\section{DEVELOPMENT OF FIGURES OF MERIT FOR COOLANT THERMAL-HYDRAULIC PERFORMANCE}

If the properties of one coolant are all superior to those of another coolant, the selection of the coolant becomes straight forward. However, each coolant generally has both superior and inferior properties. It is therefore useful to compare some key parameters that determine coolant thermal performance in the system of interest. This section discusses only coolant thermal-hydraulic characteristics; the other characteristics are discussed in later sections.

Figures of merit (FOMs) can be used in evaluating the thermal performance of the coolants (Kim et al. 2011; Sabharwall et al. 2011). Bonilla (1958) provided the FOMs based on minimal pumping power for a given coolant temperature rise as

$$
F O M=\mu^{0.2} /\left(\rho^{2} C_{P}^{2.8}\right)
$$

where

$$
\begin{aligned}
& \mu=\operatorname{viscosity}(\mathrm{Pa}-\mathrm{s}) \\
& \rho=\operatorname{density~}\left(\mathrm{kg} / \mathrm{m}^{3}\right) \\
& C p=\text { heat capacity }(\mathrm{J} / \mathrm{kg} \mathrm{K}) .
\end{aligned}
$$

Sanders (1971) proposed the following FOM based on the heat exchanger surface area:

$$
F O M=\mu^{0.2} /\left(\rho^{0.3} C_{p}^{0.6} k^{0.6}\right)
$$

Williams (2006) used the above FOMs for comparing heat transfer performance of the molten salt coolants for a Next Generation Nuclear Plant/Nuclear Hydrogen Initiative heat transfer loop.

The above two parameters (as shown in eq. 1 and 2) are very useful for comparing overall coolant heat transfer performance at the early stages of research. However, they are still not complete for evaluating all the important thermal performance parameters in the system of interest. Figure 8 shows the general thermal-hydraulic requirements for the intermediate coolant in an advanced high temperature reactor (AHTR) system, which is part of fluoride cooled high temperature reactor (FHR) class.

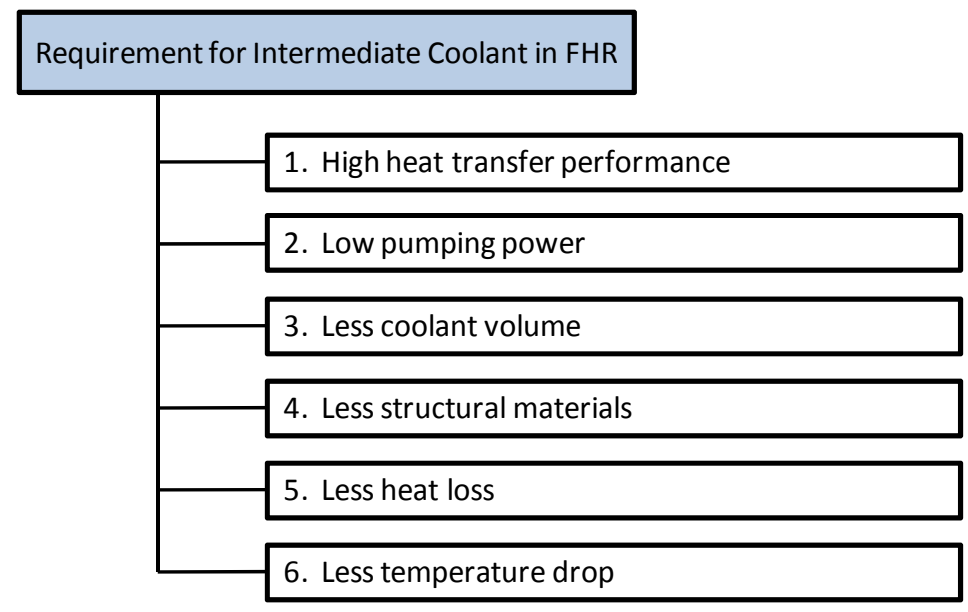

Figure 8. General thermal-hydraulic requirements for the intermediate coolant in advanced high temperature reactor systems. 
The following are general thermal-hydraulic requirements for the coolant in an AHTR:

- High heat transfer performance: Coolant should transfer heat efficiently. Good heat transfer performance leads to efficient heat transfer between the primary and the intermediate loops.

- Low pumping power: Coolant should require low pumping power to minimize efficiency loss and economic loss.

- Minimal coolant volume: Small volume of coolant is preferred for economic reasons.

- Minimal structural materials for containing coolant: Small amount of structural materials for the coolant containment is preferred for economic reasons.

- Minimal heat loss: Heat loss of the coolant should be minimized when transferring heat long distances for a more efficient system.

- Minimal temperature drop: The coolant temperature drop should be minimized when transferring heat to long distances for a more efficient system.

The above requirements are associated with the thermal-hydraulic properties including thermal conductivity, density, heat capacity, and viscosity. This study developed five different FOMs that can represent each requirement.

Figure 8 shows the basic configuration of the general intermediate heat transfer loop. Heat $(Q)$ is transferred to the coolant system through heat exchangers, increasing coolant temperature. This coolant is driven by pumps or circulators to transport the heat to several areas for use in electricity generation, chemical processes, etc. Therefore, the operating temperature and pressure of this system are generally determined and optimized by how the energy is used. However, detailed heat transfer performance, system size, and major component specifications are significantly affected by coolant type.

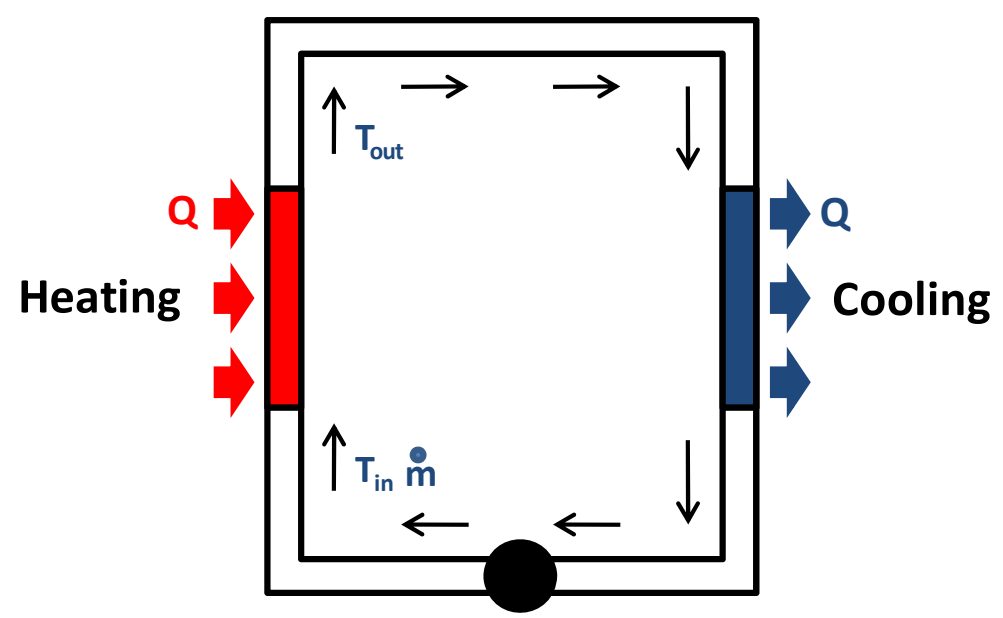

Figure 9. General configuration of an intermediate heat transfer loop.

\subsection{Heat Transfer Performance Factor: Figures of Merit for Heat Transfer Performance (FOM ${ }_{\mathrm{ht}}$ )}

The major role of any coolant is heat transfer. Therefore, heat transfer performance is one of the most important factors to consider in coolant options. Heat transfer performance of the coolants can be compared by calculating the heat transfer at the same pumping power for the given geometry. If a certain coolant has the highest heat transfer coefficient, the coolant can be considered as having the best heat transfer performance. 
The FOM for the heat transfer performance can be derived as Equation (3). Figure 10 shows a circular pipe with diameter, $\mathrm{D}$ and length, $\mathrm{L}$. In this derivation, the pumping power was assumed to be the same for the different fluids. The pumping power is expressed as

$$
P_{\text {pump }}=\frac{\Delta P \cdot \bar{Q}}{\eta}
$$

where

$$
\begin{array}{ll}
\text { Pump } & =\text { pumping power } \\
\Delta P & =\text { pressure drop } \\
\bar{Q} & =\text { volumetric flow rate } \\
\eta & =\text { pump efficiency. }
\end{array}
$$

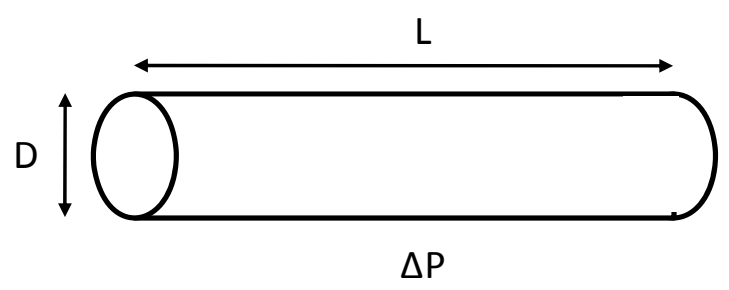

Figure 10. Geometry and input parameters for figures of merit development (heat transfer performance).

The cooling system is generally operated in the turbulent flow regime. Therefore, ignoring change of elevation, the pressure drop is expressed by (Welty et al. 1984):

$$
\Delta P=f \cdot \frac{1}{2} \rho \cdot U^{2} \cdot \frac{L}{D}
$$

where

$$
\begin{aligned}
f & =\text { friction factor (constant for the high Reynolds number) } \\
\rho & =\text { density } \\
L & =\text { channel length } \\
D & =\text { channel diameter } \\
U & =\text { flow velocity. }
\end{aligned}
$$

The friction factor (f) can be calculated by the Blasius formula for a smooth pipe as (Welty et al. 1984):

$$
f=0.316 \cdot \mathrm{Re}^{-0.25}
$$

where

$$
\operatorname{Re}=\frac{\rho \cdot U \cdot D}{\mu}
$$

The volumetric flow rate can be expressed by

$$
\bar{Q}=U \cdot A=U \cdot\left(\frac{\pi}{4} D^{2}\right)
$$


where

$A=$ channel cross-sectional area.

By inserting Equations (4), (5), (6), and (7) in Equation (3), the following expression can be obtained:

$P_{\text {pump }}=\frac{\left(f \cdot \frac{1}{2} \rho \cdot U^{2} \cdot \frac{L}{D}\right) \cdot U \cdot\left(\frac{\pi}{4} D^{2}\right)}{\eta}=\frac{\left(0.316 \cdot\left(\frac{\rho \cdot U \cdot D}{\mu}\right)^{-0.25} \cdot \frac{\pi}{8} \rho \cdot U^{3} \cdot L \cdot D\right)}{\eta}$

$=\frac{\left(\frac{0.316 \cdot \pi}{8} \rho^{0.75} \cdot U^{2.75} \cdot L \cdot D^{0.75} \cdot \mu^{0.25}\right)}{\eta}$.

Therefore, the flow velocity can be derived by:

$U=\left(\frac{\eta \cdot P_{\text {pump }}}{\left(\frac{0.316 \cdot \pi}{8} L \cdot D^{0.75}\right)}\right)^{0.36} \cdot(\rho)^{-0.27} \cdot(\mu)^{-0.09}=C_{1} \cdot(\rho)^{-0.27} \cdot(\mu)^{-0.09}$

For the given conditions, the variable $\mathrm{C}_{1}$ can be considered as constant. Therefore, the flow velocity is determined by only coolant density and viscosity.

General convective heat transfer is expressed as (Welty et al. 1984):

$Q=h \cdot S \cdot \Delta T$

where

$Q=$ heat flow from the fluid to the wall

$h=$ convective heat transfer coefficient

$S=$ heat transfer surface area

$\Delta T=$ temperature difference between bulk fluid and wall.

In the given condition, surface area $(S)$ and temperature difference $(\Delta T)$ are fixed. Therefore, the heat transfer is proportional to the heat transfer coefficient $(h)$. The heat transfer coefficient for turbulent flow is generally expressed by the Dittus-Boelter correlation (Welty et al. 1984):

$h=\frac{k}{D} \cdot N u=\frac{k}{D} \cdot\left(0.023 \operatorname{Re}^{0.8} \operatorname{Pr}^{0.4}\right)$

where

$k=$ thermal conductivity

$N u=$ Nusselt number

$R e=$ Reynolds number

$\operatorname{Pr}=$ Prandtl number. 
The Prandtl number (Pr) is defined as

$$
\operatorname{Pr}=\frac{C_{p} \cdot \mu}{k}
$$

By inserting Equations (6) and (12) in Equation (11), the heat transfer coefficient (h) can be written as

$$
h=\frac{k}{D} \cdot\left(0.023\left(\frac{\rho \cdot U \cdot D}{\mu}\right)^{0.8}\left(\frac{C_{p} \cdot \mu}{k}\right)^{0.4}\right)
$$

The velocity in Equation (13) can be replaced by Equation (9) as

$$
h=\frac{k}{D} \cdot\left(0.023\left(\frac{\rho \cdot D}{\mu}\right)^{0.8} \cdot\left(C_{1} \cdot(\rho)^{-0.27} \cdot(\mu)^{-0.09}\right)^{0.8} \cdot\left(\frac{C_{p} \cdot \mu}{k}\right)^{0.4}\right)
$$

therefore

$$
h=\left(\frac{0.023 \cdot\left(C_{1}\right)^{0.8}}{D^{0.2}}\right) \cdot(k)^{0.6} \cdot(\rho)^{0.58} \cdot\left(C_{p}\right)^{0.4} \cdot(\mu)^{-0.47}
$$

In this derivation, $\mathrm{C}_{1}$ is a constant and channel diameter $(D)$ is a fixed parameter. Therefore,

$$
h \sim(k)^{0.6} \cdot(\rho)^{0.58} \cdot\left(C_{p}\right)^{0.4} \cdot(\mu)^{-0.47}
$$

The FOM for the heat transfer performance is defined by normalization as

$$
F O M_{h t}=\frac{h}{h_{0}}
$$

where

$$
\begin{aligned}
& h=\text { heat transfer coefficient for a certain coolant } \\
& h_{0}=\text { heat transfer coefficient for a reference coolant. }
\end{aligned}
$$

therefore

$$
F O M_{h t}=\frac{(k)^{0.6} \cdot(\rho)^{0.58} \cdot\left(C_{p}\right)^{0.4} \cdot(\mu)^{-0.47}}{R_{h t, 0}}
$$

and

$$
R_{h t, 0}=\left(k_{0}\right)^{0.6} \cdot\left(\rho_{0}\right)^{0.58} \cdot\left(C_{p, 0}\right)^{0.4} \cdot\left(\mu_{0}\right)^{-0.47}
$$


According to Equation (16), the coolant shows better heat transfer performance if it has higher thermal conductivity, density, and heat capacity and lower viscosity. The sensitivity of each property for the heat transfer performance factor $\left(\mathrm{FOM}_{\mathrm{ht}}\right)$ can be calculated by normalized form as follows:

$$
\begin{aligned}
& S_{k, h t}=\frac{\partial{ }^{\prime} O M_{h t} / F O M_{h t}}{\partial k / k}=0.6 \\
& S_{\rho, h t}=\frac{\partial F O M_{h t} / F O M_{h t}}{\partial \rho / \rho}=0.58 \\
& S_{C_{p}, h t}=\frac{\partial F O M_{h t} / F O M_{h t}}{\partial C_{p} / C_{p}}=0.4 \\
& S_{\mu, h t}=\frac{\partial F O M_{h t} / F O M_{h t}}{\partial \mu / \mu}=-0.47
\end{aligned}
$$

The above results show that thermal conductivity is the most sensitive property affecting heat transfer performance, followed by coolant density, viscosity, and heat capacity, respectively.

\subsection{Pumping Factor: Figures of Merit for Pumping Power (FOM $)$}

To operate a heat transfer loop, lower pumping power is highly preferred for the coolant. This study proposes the same figure of merit provided by Bonilla (1958), in the normalized form, which is based on minimal pumping power for a given coolant temperature rise as

$$
\text { FOM }_{p}=\frac{\mu^{0.2} /\left(\rho^{2} \cdot C_{P}^{2.8}\right)}{R_{p, 0}}
$$

where

$$
R_{p, 0}=\mu_{0}^{0.2} /\left(\rho_{0}^{2} \cdot C_{P, 0}{ }^{2.8}\right) \text { (for the reference coolant) }
$$

According to Equation (25), the coolant needs less pumping power if it has higher density, higher heat capacity, and lower viscosity. The sensitivity of each property for the required pumping power factor $\left(\mathrm{FOM}_{\mathrm{p}}\right)$ can be calculated by normalized form as follows:

$$
\begin{aligned}
& S_{k, p}=\frac{\partial F O M_{p} / F O M_{p}}{\partial k / k}=0.0 \\
& S_{\rho, 0}=\frac{\partial F O M_{p} / F O M_{p}}{\partial \rho / \rho}=-2 \\
& S_{C_{p} \cdot p}=\frac{\partial F O M_{p} / F O M_{p}}{\partial C_{p} / C_{p}}=-2.8 \\
& S_{\mu, p}=\frac{\partial F O M_{p} / F O M_{p}}{\partial \mu / \mu}=0.2
\end{aligned}
$$


The above results show that heat capacity is the most important property affecting required pumping power, followed by coolant density and viscosity, respectively. Relatively, the viscosity effect is small because the friction loss in the coolant is dominated by turbulent mixing not by viscous friction. Thermal conductivity does not affect the required pumping power.

\subsection{Coolant Volume Factor: Figures of Merit for Coolant Volume (FOM $\mathrm{cv}$ )}

Since each coolant has different thermal properties, the volumes required for the coolant loops are also different, depending on the coolant types. Smaller coolant volume is usually preferred for economic reasons. The volume of the coolant is generally determined based on the given heat transfer duty and the pumping power (or friction loss). Therefore, the volumes of the coolants in the heat transfer loop can be compared by calculating the channel diameter for the same heat duty, pumping power, and pipe length.

Heat transfer in the heat transfer loop is expressed by (Welty et al. 1984):

$Q=\dot{m} \cdot C_{p} \cdot \Delta T=\left(\frac{\pi}{4} D^{2} \cdot \rho \cdot U\right) \cdot C_{p} \cdot \Delta T$

Therefore, the velocity $(U)$ can be expressed by

$U=\frac{Q}{\left(\frac{\pi}{4} D^{2} \cdot \Delta T\right) \cdot C_{p} \cdot \rho}=\left(\frac{Q}{\left(\frac{\pi}{4} D^{2} \cdot \Delta T\right)}\right) \cdot C_{p}^{-1} \cdot \rho^{-1}$

The pumping power is expressed as

$P_{\text {pump }}=\frac{\left(f \cdot \frac{1}{2} \rho \cdot U^{2} \cdot \frac{L}{D}\right) \cdot U \cdot\left(\frac{\pi}{4} D^{2}\right)}{\eta}=\frac{\left(\frac{0.316 \cdot \pi}{8} \rho^{0.75} \cdot L \cdot D^{0.75} \cdot \mu^{0.25}\right)}{\eta} \cdot U^{2.75}$

Therefore,

$P_{\text {pump }}=\frac{\left(\frac{0.316 \cdot \pi}{8} \rho^{0.75} \cdot L \cdot D^{0.75} \cdot \mu^{0.25}\right)}{\eta} \cdot\left(\left(\frac{Q}{\left(\frac{\pi}{4} D^{2} \cdot \Delta T\right)}\right) \cdot C_{p}^{-1} \cdot \rho^{-1}\right)^{2.75}$

$=\frac{Q^{2.75} \cdot\left(\frac{0.316 \cdot \pi}{8} L\right)}{\eta \cdot\left(\frac{\pi}{4} \Delta T\right)^{2.75}} \cdot(\rho)^{-2} \cdot\left(C_{p}\right)^{-2.75} \cdot(D)^{-4.75} \cdot(\mu)^{0.25}$ 
The channel diameter $(D)$ can then be calculated as

$$
D=\left(\frac{Q^{2.75} \cdot\left(\frac{0.316 \cdot \pi}{8} L\right)}{P_{\text {pump }} \cdot \eta \cdot\left(\frac{\pi}{4} \Delta T\right)^{2.75}}\right)^{0.21} \cdot(\rho)^{-0.42} \cdot\left(C_{p}\right)^{-0.58} \cdot(\mu)^{0.05}
$$

Thus, the volume of the coolant is

$$
V=\frac{\pi}{4} D^{2} L=\left(\frac{\pi}{4} L \cdot\left(\frac{Q^{2.75} \cdot\left(\frac{0.316 \cdot \pi}{8} L\right)}{P_{\text {pump }} \cdot \eta \cdot\left(\frac{\pi}{4} \Delta T\right)^{2.75}}\right)^{0.42}\right) \cdot(\rho)^{-0.84} \cdot\left(C_{p}\right)^{-1.16} \cdot(\mu)^{0.1}
$$

The FOM for the coolant volume is here defined by normalization as

$$
F O M_{c v}=\frac{V}{V_{0}}
$$

where

$$
\begin{aligned}
& V=\text { volume required for a certain coolant } \\
& V_{0}=\text { volume required for a reference coolant. }
\end{aligned}
$$

Therefore,

$$
F O M_{c v}=\frac{(\rho)^{-0.84} \cdot\left(C_{p}\right)^{-1.16} \cdot(\mu)^{0.1}}{R_{c v, 0}}
$$

where

$$
R_{c v, 0}=\left(\rho_{0}\right)^{-0.84} \cdot\left(C_{p, 0}\right)^{-1.16} \cdot\left(\mu_{0}\right)^{0.1}
$$

According to Equation (37), the coolant should have high density and high heat capacity to have small volume. This is because more heat can be stored and transferred per unit volume with a higher density and heat capacity. The sensitivity of each property for the required coolant volume factor $\left(\mathrm{FOM}_{\mathrm{cv}}\right)$ can be calculated by normalized form as follows:

$$
\begin{aligned}
& S_{k, c v}=\frac{\partial F O M_{c v} / F O M_{c v}}{\partial k / k}=0.0 \\
& S_{\rho, c v}=\frac{\partial F O M_{c v} / F O M_{c v}}{\partial \rho / \rho}=-0.84 \\
& S_{C_{p} . c v}=\frac{\partial F O M_{c v} / F O M_{c v}}{\partial C_{p} / C_{p}}=-1.16
\end{aligned}
$$


$S_{\mu, c v}=\frac{\partial F O M_{c v} / F O M_{c v}}{\partial \mu / \mu}=0.1$

The above results show that heat capacity is the most important property affecting required coolant volume, followed by coolant density and viscosity, respectively.

\subsection{Pipe Material Volume Factor: Figures of Merit for Coolant Containment Volume (FOM $\mathrm{Fcv}_{\mathrm{c}}$ )}

Depending on flow conditions (temperature and pressure), the heat transfer structure requires different pipe sizes and thickness. A larger pipe size and thickness requires more volume of structural materials leading to increased cost. In comparing required pipe material volumes for the coolant and the operating conditions, the pipe size and thickness were calculated for the same heat duty and pumping power.

Pipe diameter was already estimated in Equation (34) for the given heat duty and pumping power as

$$
D=\left(\frac{Q^{2.75} \cdot\left(\frac{0.316 \cdot \pi}{8} L\right)}{P_{\text {pump }} \cdot \eta \cdot\left(\frac{\pi}{4} \Delta T\right)^{2.75}}\right)^{0.21} \cdot(\rho)^{-0.42} \cdot\left(C_{p}\right)^{-0.58} \cdot(\mu)^{0.05}
$$

In the heat transfer loop, the pipe thickness is determined based on the mechanical stress. Mechanical stresses in the thin-walled cylindrical pipe (the vessel must have a wall thickness of no more than about $1 / 20$ (Bejan et al. 1996) are estimated as

$\sigma_{\theta}=\frac{P \cdot r}{t}$ (hoop stress)

$\sigma_{z}=\frac{P \cdot D^{2}}{(D+2 t)^{2}-D^{2}}($ axial stress $)$

$\sigma_{r}=-\frac{P}{2}($ radial stress $)$

where

$$
\begin{aligned}
& P=\text { internal pressure } \\
& r=\text { pipe radius } \\
& D=\text { average pipe diameter } \\
& t=\text { pipe thickness. }
\end{aligned}
$$


Generally, under only internal pressure, the values of axial stress and radial stress are less than hoop stress. Thus, hoop stress becomes the limiting factor for determining pipe thickness. For the same material that has the same stress criteria, the thickness of the pipe can be calculated by Equation (44) as

$$
t=\frac{P \cdot D}{2 \cdot \sigma_{\theta}}=\left(\frac{1}{2 \cdot \sigma_{\theta}} \cdot\left(\frac{Q^{2.75} \cdot\left(\frac{0.316 \cdot \pi}{8} L\right)}{P_{\text {pump }} \cdot \eta \cdot\left(\frac{\pi}{4} \Delta T\right)^{2.75}}\right)^{0.21}\right) \cdot(P) \cdot(\rho)^{-0.42} \cdot\left(C_{p}\right)^{-0.58} \cdot(\mu)^{0.05}
$$

The volume of the pipe materials per unit length can be estimated for the thin walled pipe as

$$
V_{p}=\pi \cdot D \cdot t \cdot 1=\pi \cdot\left(\frac{P}{2 \cdot \sigma_{\theta}}\right) \cdot D^{2}
$$

Therefore,

$$
V_{p}=\left(\pi \cdot\left(\frac{1}{2 \cdot \sigma_{\theta}}\right) \cdot\left(\frac{Q^{2.75} \cdot\left(\frac{0.316 \cdot \pi}{8} L\right)}{P_{\text {pump }} \cdot \eta \cdot\left(\frac{\pi}{4} \Delta T\right)^{2.75}}\right)^{0.42}\right) \cdot(P) \cdot(\rho)^{-0.84} \cdot\left(C_{p}\right)^{-1.16} \cdot(\mu)^{0.1}
$$

The FOM for the coolant volume is here defined by normalization as

$$
F O M_{c c v}=\frac{V_{p}}{V_{p, 0}}
$$

where

$V_{p}=$ volume required for a pipe materials

$V_{p, 0}=$ volume required for the reference pipe materials.

Therefore,

$$
F O M_{c c v}=\frac{(P) \cdot(\rho)^{-0.84} \cdot\left(C_{p}\right)^{-1.16} \cdot(\mu)^{0.1}}{R_{c c v, 0}}
$$

where

$$
R_{c c v, 0}=\left(P_{o}\right) \cdot\left(\rho_{0}\right)^{-0.84} \cdot\left(C_{p, 0}\right)^{-1.16} \cdot\left(\mu_{0}\right)^{0.1}
$$

According to Equation (51), the coolant should have a high density, high heat capacity, and low operating pressure to have small material volume. The sensitivity of each property for the required material volume factor $\left(\mathrm{FOM}_{\mathrm{ccv}}\right)$ can be calculated by

$$
S_{k, c c v}=\frac{\partial F O M_{c c v} / F O M_{c c v}}{\partial k / k}=0.0
$$




$$
\begin{aligned}
& S_{\rho, c c v}=\frac{\partial F O M_{c c v} / F O M_{c c v}}{\partial \rho / \rho}=-0.84 \\
& S_{C_{p} . c c v}=\frac{\partial F O M_{c c v} / F O M_{c c v}}{\partial C_{p} / C_{p}}=-1.16 \\
& S_{\mu, c c v}=\frac{\partial F O M_{c c v} / F O M_{c c v}}{\partial \mu / \mu}=0.1 \\
& S_{P, c c v}=\frac{\partial F O M_{c c v} / F O M_{c c v}}{\partial P / P}=1.0
\end{aligned}
$$

The above results show that heat capacity is the most important property affecting required material volume, followed by coolant pressure and density, respectively. Effects of viscosity and thermal conductivity are negligible.

\subsection{Heat Loss Factor: Figures of Merit for Heat Loss $\left(\mathrm{FOM}_{\mathrm{hl}}\right)$}

There are times when a heat transfer loop is required to transfer heat over very long distances. Heat loss should thus be minimized to keep high system efficiency. The heat loss for different coolants can be compared for the same heat duty and pumping power as shown in the above sections. The overall heat transfer in the heat transfer loop can be expressed by (Welty et al. 1984):

$Q=\dot{m} \cdot C_{p} \cdot \Delta T=\left(\rho \cdot U \cdot \frac{\pi}{4} D^{2}\right) \cdot C_{p} \cdot \Delta T$

Therefore, the velocity of the coolant can be expressed by

$$
U=\frac{Q}{\left(\frac{\pi}{4} \cdot D^{2} \cdot \Delta T\right) \cdot \rho \cdot C_{p}}
$$

The heat loss at a certain location can be defined by

$d Q=h \cdot(\pi \cdot D \cdot d x) \cdot\left(T-T_{w}\right)$

where

$$
\begin{aligned}
& d Q=\text { heat loss at the surface } \\
& T=\text { coolant temperature } \\
& T w=\text { pipe inner wall temperature. }
\end{aligned}
$$

Therefore,

$$
q_{\text {loss }}=\frac{d Q}{d x}=h \cdot(\pi \cdot D) \cdot\left(T-T_{w}\right)
$$


By substituting Equation (13) in Equation (61),

$$
\begin{aligned}
& q_{\text {loss }}=\frac{k}{D} \cdot\left(0.023\left(\frac{\rho \cdot U \cdot D}{\mu}\right)^{0.8}\left(\frac{C_{p} \cdot \mu}{k}\right)^{0.4}\right) \cdot(\pi \cdot D) \cdot\left(T-T_{w}\right) \\
& =\left(0.023 \pi \cdot\left(T-T_{w}\right)\right) \cdot k^{0.6} \cdot C_{p}^{0.4} \cdot \rho^{0.8} \cdot \mu^{-0.4} \cdot U^{0.8} \cdot D^{0.8}
\end{aligned}
$$

Inserting Equation (59) into Equation (62) obtains

$$
\begin{aligned}
& q_{\text {loss }}=\left(0.023 \pi \cdot\left(T-T_{w}\right)\right) \cdot k^{0.6} \cdot C_{p}^{0.4} \cdot \rho^{0.8} \cdot \mu^{-0.4} \cdot\left(\frac{Q}{\left(\frac{\pi}{4} \cdot D^{2} \cdot \Delta T\right) \cdot \rho \cdot C_{p}}\right)^{0.8} \cdot D^{0.8} \\
& \left.=\left(0.023 \pi \cdot\left(T-T_{w}\right)\right) \cdot\left(\frac{Q}{\left(\frac{\pi}{4} \cdot \Delta T\right)}\right)^{0.8}\right) \cdot k^{0.6} \cdot C_{p}^{-0.4} \cdot \mu^{-0.4} \cdot D^{-0.8}
\end{aligned}
$$

For the same heat duty and pumping power, Equation (43) can be replaced with $D$ in Equation (63) as

$$
\begin{aligned}
& q_{\text {loss }}=\left(\left(0.023 \pi \cdot\left(T-T_{w}\right)\right) \cdot\left(\frac{Q}{\left(\frac{\pi}{4} \cdot \Delta T\right)}\right)^{0.8} \cdot\left(\frac{Q^{2.75} \cdot\left(\frac{0.316 \cdot \pi}{8} L\right)}{P_{\text {pump }} \cdot \eta \cdot\left(\frac{\pi}{4} \Delta T\right)^{2.75}}\right)^{-0.17}\right) \cdot(k)^{0.6} \cdot(\mu)^{-0.44} \cdot(\rho)^{0.34} \cdot\left(C_{p}\right)^{0.06} \\
& =C_{2} \cdot(k)^{0.6} \cdot(\mu)^{-0.44} \cdot(\rho)^{0.34} \cdot\left(C_{p}\right)^{0.06}
\end{aligned}
$$

The FOM for the heat loss is here defined by normalization as

$$
\mathrm{FOM}_{h l}=\frac{q_{\text {loss }}}{q_{\text {loss }, 0}}
$$

where

$$
\begin{aligned}
& q_{\text {loss }}=\text { heat loss for a certain coolant } \\
& q_{\text {loss }, 0}=\text { heat loss for a reference coolant. }
\end{aligned}
$$

Therefore,

$$
\text { FOM }_{h l}=\frac{(k)^{0.6} \cdot(\mu)^{-0.44} \cdot(\rho)^{0.34} \cdot\left(C_{p}\right)^{0.06}}{R_{h l, 0}}
$$


where

$$
R_{h l, 0}=\left(k_{0}\right)^{0.6} \cdot\left(\mu_{0}\right)^{-0.44} \cdot\left(\rho_{0}\right)^{0.34} \cdot\left(C_{p, 0}\right)^{0.06}
$$

According to Equation (66), the coolant heat loss increases with thermal conductivity and decreases with heat capacity, density, and viscosity. The sensitivity of each property for the heat loss factor $\left(\mathrm{FOM}_{\mathrm{hl}}\right) \mathrm{can}$ be calculated in normalized form as

$$
\begin{aligned}
& S_{k, h l}=\frac{\partial F O M_{h l} / F O M_{h l}}{\partial k / k}=0.6 \\
& S_{\rho, h l}=\frac{\partial F O M_{h l} / F O M_{h l}}{\partial \rho / \rho}=0.34 \\
& S_{C_{p}, h l}=\frac{\partial F O M_{h l} / F O M_{h l}}{\partial C_{p} / C_{p}}=0.06 \\
& S_{\mu, h l}=\frac{\partial F O M_{h l} / F O M_{h l}}{\partial \mu / \mu}=-0.44
\end{aligned}
$$

The above results show that thermal conductivity is the most important property affecting heat loss of coolant followed by viscosity and coolant density, respectively. The effect of heat capacity is negligible.

\subsection{Temperature Drop Factor: Figures of Merit for Temperature Drop (FOM $\mathbf{d t})$}

A heat transfer loop is required to transfer heat a very long distance with little temperature drop in order to minimize efficiency loss. The temperature drop of the coolants can be compared at the same heat duty and pumping power as shown in the above section. The temperature drop of the coolant originates from heat loss. Therefore, starting from Equation (61) and rearranging as follows:

$q_{\text {loss }}=\frac{d Q}{d x}=\dot{m} \cdot C_{p} \cdot \frac{d T}{d x}=h \cdot(\pi \cdot D) \cdot\left(T-T_{w}\right)$

Therefore,

$\frac{d T}{d x}=\frac{h \cdot(\pi \cdot D) \cdot\left(T-T_{w}\right)}{\dot{m} \cdot C_{p}}=\frac{h \cdot(\pi \cdot D) \cdot\left(T-T_{w}\right)}{Q / \Delta T}$

where

$\dot{m} \cdot C_{p}=\frac{Q}{\Delta T}$

For the same heat duty and operating conditions, Equation (74) is fixed. Therefore, the temperature drop Equation (74) has the same form as the heat loss Equation (61) except it is constant.

The FOM for the temperature drop is here defined by normalization as

$$
\text { FOM }_{d t}=\frac{(d T / d x)}{(d T / d x)_{0}}
$$


where

$$
\begin{aligned}
& d T / d x=\text { temperature drop per unit length for a certain coolant } \\
& (d T / d T)_{0}=\text { temperature drop per unit length for the reference coolant. }
\end{aligned}
$$

Therefore,

$$
F O M_{d t}=\frac{(k)^{0.6} \cdot(\mu)^{-0.44} \cdot(\rho)^{0.34} \cdot\left(C_{p}\right)^{0.06}}{R_{d t, 0}}
$$

where

$$
R_{d t, 0}=\left(k_{0}\right)^{0.6} \cdot\left(\mu_{0}\right)^{-0.44} \cdot\left(\rho_{0}\right)^{0.34} \cdot\left(C_{p, 0}\right)^{0.06}
$$

According to Equation (77), the coolant temperature drop increases with thermal conductivity and decreases with heat capacity, density, and viscosity. The sensitivity of each property for the temperature drop factor $\left(\mathrm{FOM}_{\mathrm{dt}}\right)$ can be calculated by normalized form as

$$
\begin{aligned}
& S_{k, d t}=\frac{\partial F O M_{d t} / F O M_{d t}}{\partial k / k}=0.6 \\
& S_{\rho, d t}=\frac{\partial F O M_{d t} / F O M_{d t}}{\partial \rho / \rho}=0.34 \\
& S_{C_{p} . d t}=\frac{\partial F O M_{d t} / F O M_{d t}}{\partial C_{p} / C_{p}}=0.06 \\
& S_{\mu, d t}=\frac{\partial F O M_{d t} / F O M_{d t}}{\partial \mu / \mu}=-0.44
\end{aligned}
$$

The above results show that thermal conductivity is the most important property affecting temperature drop, followed by viscosity and coolant density, respectively. The effect of heat capacity is negligible.

\subsection{Summary of Figures of Merit for Heat Transfer Coolant}

Table 1 summarizes all of the FOMs derived and proposed for the intermediate heat transfer coolants. This table lists six FOMs and sensitivities for various coolant properties. Based on the FOMs summarized, heat transfer performance, pumping power, coolant volume, pipe material volume, coolant heat loss, and coolant temperature drop can be compared easily and quantitatively for the same heat duty and pumping power requirements. A positive sensitivity value indicates that the FOM increases with the properties while negative sensitivity value indicates that the FOM decreases with the properties, respectively. The values of the sensitivities show how much the FOMs are affected by the properties. If the sensitivity is higher, the FOM is more significantly affected by that property. From this table, the effects of properties on the thermal-hydraulic performance of the coolants can be interpreted as follows:

- $\quad \mathrm{S}_{\mathrm{k}}$ - Increasing thermal conductivity can increase heat transfer performance by an order of 0.6 , but it also increases the heat loss and temperature drop of the coolant at the same rate.

- $\mathrm{S}_{\rho}$ - Increasing coolant density can increase heat transfer performance and reduce coolant volume by orders of 0.58 and 0.84 respectively, but it also decreases pumping power by an order of 2 . 
- $\mathrm{S}_{\mathrm{Cp}}$ - Increasing heat capacity can increase heat transfer performance and significantly reduce coolant/material volume by orders of 0.4 and 1.16, respectively, while increases of heat loss and temperature drop are negligible (order $=0.06$ ). It also decreases pumping power by an order of 2.8 .

- $\mathrm{S}_{\mu}$ - Increasing viscosity increases pumping power slightly $(0.2)$ and significantly reduces heat transfer performance (0.47), but it also slightly increases coolant volume by 0.1 .

- $\mathrm{S}_{\mathrm{P}}$ - Increasing internal pressure significantly increases material volume by order of 1 .

Table 1. Summary of figures of merit for heat transfer coolant.

\begin{tabular}{|c|c|c|c|c|c|}
\hline \multirow[b]{2}{*}{ Figures of Merit } & \multicolumn{5}{|c|}{ Sensitivity of Properties } \\
\hline & $\mathrm{S}_{\mathrm{k}}$ & $\mathrm{S}_{\rho}$ & $\mathrm{S}_{\mathrm{Cp}}$ & $\mathrm{S}_{\mu}$ & $\mathrm{S}_{\mathrm{P}}$ \\
\hline $\begin{array}{l}\text { Heat transfer performance factor }\left(F O M_{h t} \text { : }\right. \\
F O M_{h t}=\frac{(k)^{0.6} \cdot(\rho)^{0.58} \cdot\left(C_{p}\right)^{0.4} \cdot(\mu)^{-0.47}}{R_{h t, 0}}\end{array}$ & 0.6 & 0.58 & 0.4 & -0.47 & 0.0 \\
\hline $\begin{array}{l}\text { Pumping factor }\left(F O M_{p}\right) \text { : } \\
F_{O M}=\frac{\rho^{-2} \cdot C_{P}^{-2.8} \cdot \mu^{0.2}}{R_{p, 0}}\end{array}$ & 0.0 & -2 & -2.8 & 0.2 & 0.0 \\
\hline $\begin{array}{l}\text { Coolant volume factor }\left(F O M_{c v}\right): \\
F O M_{c v}=\frac{(\rho)^{-0.84} \cdot\left(C_{p}\right)^{-1.16} \cdot(\mu)^{0.1}}{R_{c v, 0}}\end{array}$ & 0.0 & -0.84 & -1.16 & 0.1 & 0.0 \\
\hline $\begin{array}{l}\text { Material volume factor }\left(F O M_{c c v}\right) \text { : } \\
F O M_{c c v}=\frac{(P) \cdot(\rho)^{-0.84} \cdot\left(C_{p}\right)^{-1.16} \cdot(\mu)^{0.1}}{R_{c c v, 0}}\end{array}$ & 0.0 & -0.84 & -1.16 & 0.1 & 1.0 \\
\hline $\begin{array}{l}\text { Heat loss factor }\left(F O M_{h l}\right) \text { : } \\
F O M_{h l}=\frac{(k)^{0.6} \cdot(\rho)^{0.34} \cdot\left(C_{p}\right)^{0.06} \cdot(\mu)^{-0.44}}{R_{h l, 0}}\end{array}$ & 0.6 & 0.34 & 0.06 & -0.44 & 0.0 \\
\hline $\begin{array}{l}\text { Temperature drop factor }\left(F O M_{d t}\right) \text { : } \\
F O M_{d t}=\frac{(k)^{0.6} \cdot(\rho)^{0.34} \cdot\left(c_{p}\right)^{0.06} \cdot(\mu)^{-0.44}}{R_{d t, 0}}\end{array}$ & 0.6 & 0.34 & 0.06 & -0.44 & 0.0 \\
\hline
\end{tabular}




\section{COMPONENT SCALING}

This section provides a methodology for scaling prototype thermal hydraulic components to lab scale (referred as model). One of the key components for energy integration is a heat exchanger, thus this section mainly focuses on heat exchangers and is used as an example to illustrate a broader component-level scaling methodology.

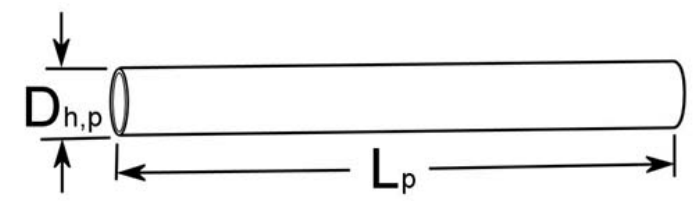

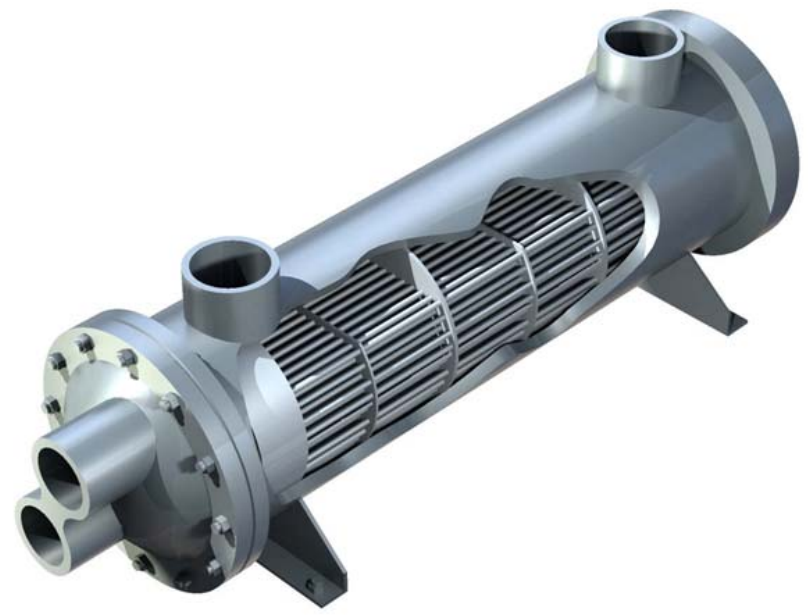

PROTOTYPE (Full Size)
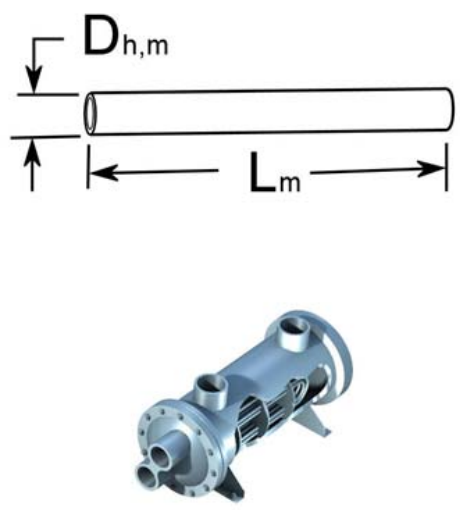

LAB SCALE MODEL

Figure 11. Simple illustration of a prototype and a model heat exchanger.

Geometrical similarity is assumed, such that length and diameter are scaled by a known factor $\rightarrow \mathrm{S}_{\mathrm{f}}$ (referred as scaling factor). Prototype (full scale) values are represented by $(p)$ and model (scaled) values are represented by $(m)$.

Table 2. Parameter definitions for component scaling.

\begin{tabular}{|l|l|c|}
\hline \multicolumn{1}{|c|}{ Parameters } & \multicolumn{1}{c|}{ Value } & Units \\
\hline Hydraulic diameter $\left(\mathrm{D}_{\mathrm{h}}\right)$ & $\mathrm{D}_{\mathrm{h}, \mathrm{m}}=\mathrm{D}_{\mathrm{h}, \mathrm{p}} / \mathrm{S}_{\mathrm{f}}$ & $\mathrm{m}$ \\
Length $(\mathrm{L})$ & $\mathrm{L}_{\mathrm{m}}=\mathrm{L}_{\mathrm{p}} / \mathrm{S}_{\mathrm{f}}$ & $\mathrm{m}$ \\
Flow area $\left(\mathrm{A}_{\mathrm{f}}\right)$ & $\mathrm{A}_{\mathrm{f}, \mathrm{m}}=\mathrm{A}_{\mathrm{f}, \mathrm{p}} / \mathrm{S}_{\mathrm{f}}^{2}$ & $\mathrm{~m}^{2}$ \\
Surface area $\left(\mathrm{A}_{\mathrm{s}}\right)$ & $\mathrm{A}_{\mathrm{s}, \mathrm{m}}=\mathrm{A}_{\mathrm{s}, \mathrm{p}} / \mathrm{S}_{\mathrm{f}}^{2}$ & $\mathrm{~m}^{2}$ \\
Volume $(\mathrm{V})$ & $\mathrm{V}_{\mathrm{m}}=\mathrm{V}_{\mathrm{p}} / \mathrm{S}_{\mathrm{f}}^{3}$ & $\mathrm{~m}^{3}$ \\
\hline
\end{tabular}


Assumptions for the analysis:

- Inlet temperature for both the prototype and model are same

- Coolant and operating conditions are the same.

For single-phase forced-convection fluid flow the Reynold's number should be preserved, such that

$$
\begin{aligned}
& \frac{R e_{m}}{R e_{p}}=\frac{\left(\frac{\rho_{m} u_{m} D_{h, m}}{\mu_{m}}\right)}{\left(\frac{\rho_{p} u_{p} D_{h, p}}{\mu_{p}}\right)}=\left(\frac{D_{h, m} \dot{m}_{m}}{A_{f, m} \mu_{m}}\right)\left(\frac{A_{f, p} \mu_{p}}{D_{h, p} \dot{m}_{p}}\right)=1 \\
& =\left(\frac{\dot{m}_{m}}{\dot{m}_{p}}\right)\left(\frac{D_{h, m}}{D_{h, p}}\right)\left(\frac{A_{f, p} \mu_{p}}{A_{f, m} \mu_{m}}\right)=1
\end{aligned}
$$

Since the fluid used in the prototype and the model are same and the operating conditions (e.g., pressure, temperature) are identical, the equation further reduces to

$=\left(\frac{\dot{m}_{m}}{\dot{m}_{p}}\right)\left(\frac{1}{S_{f}}\right)\left(S_{f}^{2}\right)=1$

Thus,

$\dot{m}_{m}=\frac{\dot{m}_{p}}{S_{f}}$

Substituting mass flow rate in terms of density, velocity and flow area, yields the velocity ratio

$\dot{m}_{m}=\rho_{m} A_{f, m} u_{m}$

$\dot{m}_{p}=\rho_{p} A_{f, p} u_{p}$

$\frac{u_{m}}{u_{p}}=S_{f}$

For heat transfer and pressure drop in fully developed laminar flow, the Nusselt number $(N u)$ is constant and friction factor $(f)$ is a function of Reynolds number, which is matched in the model and prototype.

The rate of overall heat transfer $(U)$ can be scaled as:

$\frac{U_{m}}{U_{p}}=\frac{h_{m}}{h_{p}}=\frac{N u_{m}}{N u_{p}} \frac{D_{h, p}}{D_{h, m}}=\frac{D_{h, p}}{D_{h, m}}=S_{f}$

The core pressure drop evaluation (frictional pressure drop) can be written as:

$\frac{\Delta P}{L}=\frac{f \rho u^{2}}{2 D_{h}}$

$\frac{\Delta P_{m}}{\Delta P_{p}}=\frac{f_{m}}{f_{p}} \frac{u_{m}^{2}}{u_{p}^{2}} \frac{\left(L / D_{h}\right)_{m}}{\left(L / D_{h}\right)_{p}}$

$\frac{\Delta P_{m}}{\Delta P_{p}}=(1)\left(S_{f}\right)^{2}(1)=S_{f}^{2}$ 
This example is a simple illustration of component scaling for single-phase forced convection. A similar methodology can be used to obtain heat transfer and pressure drop relationships for turbulent flow. Reynolds number provides a measure of the ratio of inertial to viscous forces acting on a fluid element and is of significance for forced convection. The Grashof number (Gr) represents the ratio of buoyancy forces to viscous forces acting on the fluid and is of main significance for natural convection phenomena. Natural convection and natural circulation drive important passive safety features for advanced reactors and thus are considered in the following illustration. In this case, since we are focusing on scaling for components, such as heat exchangers, only Re and Gr numbers are conserved. An integral system scaling methodology for the entire loop is described in the next section, where the Richardson number (Ri) is preserved, as full-loop natural circulation requires matching of Ri number.

If we take into consideration the temperature dependence of properties, the averaged property value can be obtained as

$\frac{1}{\mathrm{~T}_{\mathrm{b}}-\mathrm{T}_{\mathrm{a}}} \int_{\mathrm{T}_{\mathrm{a}}}^{\mathrm{T}_{\mathrm{b}}} \rho(\mathrm{T}) \mathrm{dT}$

$\dot{\mathrm{m}}_{\mathrm{m}}=\overline{\rho_{\mathrm{m}}} \mathrm{A}_{\mathrm{f}, \mathrm{m}} \mathrm{u}_{\mathrm{m}}$

where $\overline{\rho_{m}}$ is the average property value, in this study the properties are assumed to be constant with respect to temperature (i.e., $\overline{\rho_{m}} \sim \rho_{m}$ )

$\dot{\mathrm{m}}_{\mathrm{m}}=\rho_{\mathrm{m}} \mathrm{A}_{\mathrm{f}, \mathrm{m}} \mathrm{u}_{\mathrm{m}}=\rho_{\mathrm{m}}\left(\frac{\pi \mathrm{D}_{\mathrm{h}, \mathrm{m}}^{2}}{4}\right) \mathrm{u}_{\mathrm{m}}$

For the forced convection case, the Reynolds number should be matched between the model and the prototype.

$\frac{\operatorname{Re}_{\mathrm{m}}}{\operatorname{Re}_{\mathrm{p}}}=1$

$\frac{\left(u_{m} D_{h, m}\right)}{\left(u_{p} D_{h, p}\right)}\left(\frac{\rho_{m}}{\mu_{m}}\right)\left(\frac{\mu_{p}}{\rho_{p}}\right)=1$

$\frac{\left(u_{m} D_{h, m}\right)}{\left(u_{p} D_{h, p}\right)}=\frac{v_{m}}{v_{p}}$

where, $v$ is the kinematic viscosity, $v=\frac{\mu}{\rho}$

The fluid and the hydraulic diameter for the prototype are known (i.e., the scaling ratio), the relation for the model velocity with respect to velocity in the prototype can be obtained, using Equation (94).

For natural convection, the Gr number should be conserved

$\frac{\mathrm{Gr}_{\mathrm{m}}}{\mathrm{Gr}_{\mathrm{p}}}=\frac{\left(\frac{\mathrm{g} \beta \Delta \mathrm{T} \mathrm{L}^{3}}{v^{2}}\right)_{\mathrm{m}}}{\left(\frac{\mathrm{g} \beta \Delta \mathrm{T} \mathrm{L}^{3}}{v^{2}}\right)_{\mathrm{p}}}=1$

Further, decomposing the Gr number into two dimensionless group $\left(\frac{\mathrm{gL}^{3}}{v^{2}}\right)$ and $(\beta \Delta \mathrm{T})$ 


$$
\frac{\mathrm{Gr}_{\mathrm{m}}}{\mathrm{Gr}_{\mathrm{p}}}=\frac{\left(\frac{\mathrm{g} \mathrm{L^{3 }}}{v^{2}}\right)_{\mathrm{m}}(\beta \Delta \mathrm{T})_{\mathrm{m}}}{\left(\frac{\mathrm{g} \mathrm{L^{3 }}}{v^{2}}\right)_{\mathrm{p}}(\beta \Delta \mathrm{T})_{\mathrm{p}}}=1
$$

If the same $\Delta \mathrm{T}$ is maintained for both the prototype and the model, Equation (96), can be further reduced to

$$
\frac{L_{m}}{L_{p}}=\left(\frac{\beta_{\mathrm{p}}}{\beta_{\mathrm{m}}}\right)^{\frac{1}{3}}\left(\frac{v_{\mathrm{m}}}{v_{\mathrm{p}}}\right)^{\frac{2}{3}}
$$

Therefore, if we know the thermal expansion coefficients for the prototype and model fluids, we can determine the required length ratio.

If we must conserve both the Re number and Gr number, we obtain

$\frac{D_{m}}{D_{p}}=\left(\frac{v_{m}}{v_{p}}\right)\left(\frac{u_{p}}{u_{m}}\right)($ from Equation [94])

$\frac{v_{\mathrm{m}}}{v_{\mathrm{p}}}=\left(\frac{\beta_{\mathrm{m}}}{\beta_{\mathrm{p}}}\right)^{\frac{1}{2}}\left(\frac{L_{m}}{L_{p}}\right)^{\frac{3}{2}}$ (from Equation [97])

Therefore,

$\frac{D_{m}}{D_{p}}=\left(\frac{\beta_{\mathrm{m}}}{\beta_{\mathrm{p}}}\right)^{\frac{1}{2}}\left(\frac{L_{m}}{L_{p}}\right)^{\frac{3}{2}}\left(\frac{u_{p}}{u_{m}}\right)$

Thus, we can use Equation (100), to establish the relation of the unknown quantity of the model with respect to prototype. 


\section{INTEGRAL FACILITY SCALING ANALYSIS}

Many of the experimental capabilities identified in this report, including the proposed ARTIST facility, are primarily intended for component and separate-effects testing. Scaling of single components involves matching the relevant nondimensional parameters between the model and the prototype for the component of interest. For single-phase steady-state forced-convection thermal-hydraulic components, these parameters include the Reynolds number and Prandtl number. For single-phase components with natural convection, the Rayleigh number must be added to the list. For components with two-phase flow and boiling or condensation heat transfer, additional parameters must be added including the Jakob number, the Bond number, the Weber number, and others. In addition, geometrical parameters such as orientation (vertical or horizontal) become explicitly significant for two-phase thermal hydraulics. If we are interested in the transient behavior of thermal-hydraulic components, the scaling analysis of even a single component is significantly more complicated, and parameters related to heat conduction in the solid material must be considered.

In some cases we may be interested in performing integrated system experiments in which the coupled behavior of two or more components or subsystems may be of interest. Ideally, a perfectly scaled miniature version (perhaps at reduced pressure and temperature) of a much larger multi-component system of interest could be built that would faithfully reproduce all of the important phenomena associated with integrated operation of the full-scale system, including two-phase and transient behavior. Unfortunately, this idealized approach is not achievable due to the multiple disparate scales of the phenomena of interest. For complex multi-component multi-phase systems, such as nuclear steam supply systems, it is generally not possible to match all of the relevant nondimensional parameters in subscale models. Scaling analysis of these integrated systems typically requires the introduction of many additional nondimensional ( $\mathrm{Pi}$ or $\pi$ ) groups. Therefore, compromises must be made and an assessment of the importance of scaling distortions must be performed.

A brief summary of integrated-component scaling analysis for the assessment of the thermal-hydraulic behavior of a complex transient two-phase system is presented in this section. The example under consideration is a scaled nuclear thermal hydraulic facility (model) versus a full-scale system (prototype). The analysis was developed for small modular nuclear reactor systems, but the general methodology is also applicable to other integrated systems.

This discussion follows the H2TS methodology outlined by Reyes (2005) and Reyes and Hochreiter (1998), which is based on the USNRC Severe Accident Scaling Methodology (Zuber 1991). The first step in this methodology is to identify the experimental objectives that justify/necessitate the construction of the scaled facility. For example, some new small modular reactors utilize a highly integrated design in which the reactor core, control rod drive mechanisms, reactor coolant pump impellers, pressurizer, and steam generator are contained in a single vessel. The analyses of the various safety-relevant events are therefore, somewhat different than those of traditional PWRs, requiring an expansion of the existing data base to gain confidence in the design and code predictions. The purpose of scaled facilities is therefore to provide this expanded database, to confirm the performance of the engineered passive safety features, and to support transient computer code validation and verification. Operation of the scaled facility will also provide valuable insight into transient system behavior, and will support the development of abnormal and emergency operating procedures.

Hierarchy is defined in Zuber (1991) with respect to the regulatory objective of establishing the safety case for a particular nuclear power plant application, using the vernacular of "top-down" and "bottom-up" to address knowledge organization. The top-down effort appears as a hierarchical decomposition of a design/event tandem, established qualitatively from subject matter experts and seeking a modeling domain from the perspective of the variables affecting the principal figures-of-merit. With the bottom-up effort all problem variables are evaluated to quantify the range of the principal figures-of-merit. 
Instrumental in this methodology is the Phenomena Identification and Ranking Table (PIRT). The PIRT process formalizes the identification of "important" phenomena to be replicated by scaled facilities.

The two tiers of the H2TS methodology are the top-down or system approach and the bottom-up or process approach. The top-down approach yields a set of nondimensional scaling parameters that are expressed as characteristic time ratios (also called Pi Groups). The nondimensional parameters are derived from the governing conservation equations for mass, momentum, and energy, expressed at the scale of the phenomenon or process of interest. The second tier bottom-up approach provides more detailed localized analyses of the important processes. The two tiers provide an overall analysis methodology that is objective, tractable and technically justifiable.

Where the PIRT process significantly relies on the observational subjectivity of the subject matter expert, the HT2S emphasizes a physically-based hierarchy of the form:

- Domain synthesis

- System

- Subsystem

- Modules

- Constituents

- Phases

- Geometry

- Topology

- Domain analysis

- Fields

- Transport processes.

This presentation of the physically-based hierarchy takes some liberties with the original report by separating the categories into distinct synthesis and analysis domains. Analysis can presumably be applied at any scale.

\subsection{Phenomena Identification and Ranking Table Process}

The second step in the scaling analysis methodology is the development of a PIRT. Since the geometric and thermal-hydraulic details of these systems are extremely complex, it is impossible to achieve exact similitude between the scaled facility (the "model") and the full-scale prototype (the reactor system). Therefore, the scaled facility must be designed to ensure that the most important and relevant phenomena are properly represented. The objective of the PIRT process is to identify the important operational modes to be explored with the scaled facility and to rank the phenomena associated with each of those modes in terms of their importance to plant safety and operation.

The PIRT process, described in Larson et al. 2007, is subdivided into a series of 9 steps:

1. Define issues driving the PIRT

2. Define PIRT objectives

3. Review relevant background information

4. Divide scenarios into phases; list components important to each phase

5. Select the key figure of merit used to judge importance

6. Identify plausible phenomena

7. Assign importance of phenomena relative to figure of merit; document rationale 
8. Assess current level of knowledge regarding each phenomenon

9. Document PIRT results.

Following Step 4 in the PIRT process, the scenario of interest can be divided into phases that describe the overall transient. For example, considering light water reactor safety-relevant scenarios, consider a small-break loss-of-coolant accident with the following phases:

1. Initial break, blowdown, depressurization, flashing.

2. Depressurization to intermediate pressure, intermediate pressure injection from accumulator flooding tanks.

3. Further depressurization, automatic depressurization system valves open, passive gravity water feed from elevated core makeup tanks.

4. Refilling of reactor coolant system, two-phase natural circulation.

5. Long-term passive coolant makeup from boil-off in the core, steam venting to containment.

6. Following this step, the key FOM must be selected to judge the importance of each phenomenon relative to this scenario. Examples include peak cladding temperature, reactor cooling system water inventory. The remainder of the PIRT focuses on Steps 6-8 of the process.

\subsection{Top-Down Scaling Analysis}

Thermal-hydraulic test facilities can potentially be operated in different modes including forced convection, single-phase natural circulation, and two-phase natural circulation. Natural circulation is an example of an integrated system in which the characteristics of all of the components in the loop contribute to the overall loop performance as coupled entities. Natural circulation is extremely important for various safety-relevant transients in nuclear reactor systems and potentially for various hybrid systems. Accurate simulation of natural circulation-driven flow and heat transfer in reduced-scale facilities requires proper scaling. The sections below provide a method for evaluating scaling and distortion in reduced-scale facilities operating in single- or two-phase natural circulation. The analyses are derived for reactor system test loops, but they can also be applied more generally for any test loop operating in natural circulation.

\subsubsection{Single-Phase Natural Circulation}

\subsubsection{Governing Equations and Nondimensional Parameters}

In reactor systems, single-phase natural circulation is important for scenarios that do not involve rapid depressurization such as loss-of-offsite-power mitigated by residual heat removal systems. Following the scaling analysis presented in Reyes (2005), the one-dimensional loop momentum balance equation for single-phase natural circulation is given by:

$$
\sum_{i=1}^{N}\left(\frac{l_{i}}{a_{i}}\right) \cdot \frac{d \dot{m}}{d t}=\beta g \rho_{l}\left(T_{H}-T_{c}\right) L_{t h}-\frac{\dot{m}^{2}}{\rho_{l} a_{c}^{2}} \sum_{i=1}^{N}\left[\frac{1}{2}\left(\frac{f l}{d_{h}}+K\right)_{i}\left(\frac{a_{c}}{a_{i}}\right)^{2}\right]
$$

where the $i$ subscripts refer to the $i t h$ component and $L_{t h}$ is the thermal center length. The core cross-sectional flow area, $a_{c}$, is used as the reference flow area (note that all variables are also defined in the Nomenclature section). 
Each term in the momentum equation has dimensions of mass flux times velocity or momentum rate of change per unit area or force per unit area (all equivalent). The left-hand side represents the rate of change of momentum and the right-hand side represents the difference between the buoyancy and loss forces. At steady state, the natural circulation flow is established as a balance between the buoyancy driving force and the flow losses.

A simplified one-dimensional energy equation for the system in single-phase natural circulation is presented in Reyes (2005):

$C_{v l} M_{s y s} \frac{d\left(T_{M}-T_{C}\right)}{d t}=\dot{m} C_{p l}\left(T_{H}-T_{C}\right)-q_{S G}-q_{\text {loss }}$

The left-hand side of this equation represents the rate of change of thermal energy for a characteristic system liquid mass having a mixed mean temperature of $T_{M}$. The right-hand side represents the difference between the convective source term, representing heat generation in the core, and the heat losses through the steam generator and elsewhere. Each term in this equation has dimensions of power.

The momentum and energy equations are nondimensionalized using the loop time constant for the time variable and initial conditions for mass flow rate, flow losses, temperature differences, and heat losses (Reyes 2005). The loop time constant is

$$
\tau_{\text {loop }}=\sum_{i=1}^{N} \frac{l_{i}}{u_{i}}=\sum_{i=1}^{N} \tau_{i}=\frac{M_{\text {sys }}}{\dot{m}_{o}}=\frac{M_{\text {sys }}}{\rho_{l} u_{c o} a_{c}}
$$

The nondimensionalization procedure yields a number of nondimensional groups:

$\underline{\text { Loop reference length number }}$

$$
\Pi_{\mathrm{L}}=\sum_{i=1}^{N} \frac{l_{i}}{l_{\text {ref }}} \frac{a_{c}}{a_{i}} \text { where } l_{\text {ref }}=\frac{M_{\text {sys }}}{\rho_{l} a_{c}}
$$

Richardson number

$$
R i=\frac{\beta g\left(T_{H}-T_{C}\right) L_{t h}}{u_{c o}^{2}}=\frac{\beta g q_{c o} L_{t h}}{\rho_{l} a_{c} c_{p l} u_{c o}^{3}}
$$

The equivalence of these two forms of the Richardson number follows from an energy balance across the core:

$q_{c o}=\rho_{l} a_{c} u_{c o} C_{p l}\left(T_{H}-T_{c}\right)=\dot{m}_{c o} C_{p l}\left(T_{H}-T_{C}\right)$

In general, the Richardson number represents the ratio of buoyancy forces to inertial forces. It can also be expressed in terms of the Grashof and Reynolds numbers:

$$
R i=\frac{\beta g \Delta T L_{c}}{u^{2}}=\frac{\frac{g \beta \Delta T L^{3}}{v^{2}}}{\left(\frac{u L}{v}\right)^{2}}=\frac{G r}{R e^{2}}=\frac{u_{o}^{2}}{u^{2}}=\frac{u_{o}^{2}}{u_{c o}^{2}}
$$

Where $u_{o}$ is the characteristic velocity for natural convection and $u$ is a local velocity. For the reactor system natural circulation

$u_{o}=\sqrt{\beta g\left(T_{H}-T_{C}\right) L_{t h}}$ and $u=u_{c o}$ 
Loop resistance number:

$$
\Pi_{F l}=\sum_{i=1}^{N}\left\{\frac{1}{2}\left(\frac{f l}{d_{h}}+K\right)_{i}\left(\frac{a_{c}}{a_{i}}\right)^{2}\right\}_{o}
$$

Loop energy ratio:

$$
\Pi_{T}=\frac{\left(T_{H}-T_{C}\right)_{o}}{\left(T_{M}-T_{C}\right)_{o}}
$$

$\underline{\text { Steam generator transport number: }}$

$$
\Pi_{S G}=\frac{q_{S G o}}{\rho_{l} u_{c o} a_{c} C_{p l}\left(T_{M}-T_{c}\right)_{o}}
$$

which represents the ratio of the heat transfer to the steam generator to the core power heat input.

Loop heat loss number:

$$
\Pi_{L o s s}=\frac{q_{l o s s, o}}{\rho_{l} u_{c o} a_{c} C_{p l}\left(T_{M}-T_{c}\right)_{o}}
$$

which represents the ratio of the other system heat losses to the core heating.

The steady-state solution of the nondimensionalized momentum equation is simply:

$R i=\Pi_{F l}$

or

$$
\frac{\beta g q_{c o} L_{t h}}{\rho_{l} a_{c} C_{p l} u_{c o}^{3}}=\Pi_{F l}
$$

which provides a solution for the steady-state core inlet velocity:

$$
u_{c o}=\left(\frac{\beta q_{c o} L_{t h} g}{\rho_{l} a_{c} C_{p l} \Pi_{F l}}\right)^{1 / 3}
$$

If the loop resistance number is known, from calculation or simulation, the core inlet velocity can be calculated, as well, as the Richardson number and the loop time constant. Experimental validation can be achieved through direct measurement of the core inlet velocity in the scaled facility (if this is possible to do in a non-intrusive fashion). Note that Equation (115) for core inlet velocity is equivalent to Ishii and Kataoka's (1984) Equation (18).

\subsubsection{Geometry-Level Governing Equations and Nondimensional Parameters}

The previous section examined scaling of the primary loop natural circulation phenomena using a simplified overall energy equation. This section examines fluid-solid transient heat transfer processes and the associated scaling issues. Consideration of this energy transfer mechanism necessitates the inclusion of an energy equation for both the fluid (single-phase or two-phase) and the solid. With the added complexity, several additional nondimensional parameters emerge from the governing equations. Ishii's (Ishii and Kataoka 1984) analysis uses this approach for both single-phase and two-phase natural circulation. The analysis for two-phase natural circulation is also detailed in Reyes and Hochreiter (1998) with a focus on core heat transfer. 
For single-phase natural circulation, the constituent fluid energy equation can be written as

$\rho C_{p}\left\{\frac{\partial T}{\partial t}+u \frac{\partial T}{\partial z}\right\}=\frac{4 h_{\text {conv }}}{d_{h}}\left(T_{s}-T\right)$

and the solid energy equation is

$\rho_{s} C_{p s} \frac{\partial T_{s}}{d t}+k_{s} \nabla^{2} T_{s}=\dot{q}_{s}$

with the boundary condition:

$-k_{s} \frac{\partial T_{S}}{\partial y}=h_{c o n v}\left(T_{s}-T\right)$

The momentum equation given by Equation (101) still applies. The constituent energy equations can be nondimensionalized using the core inlet velocity as the reference velocity, core height as the reference length, core temperature difference as the reference temperature difference, core flow area as the reference flow area, and the conduction thickness, $\delta$, as the reference thermal depth for the solid (Ishii and Kataoka 1984). The conduction thickness is defined as the ratio of the solid cross-sectional area of each section divided by the wetted perimeter:

$\delta_{i}=\frac{a_{s_{i}}}{P_{w}}$

This definition is similar to the definition of hydraulic diameter (flow cross sectional area divided by wetted perimeter). Conduction thickness and hydraulic diameter are therefore related by:

$d_{h_{i}}=4 \delta_{i} \frac{a_{i}}{a_{s_{i}}}$

The nondimensionalization of the fluid and solid energy equations and the boundary condition yield the following additional nondimensional scaling parameters:

Modified Stanton number:

$S t_{i}=\left(\frac{4 h_{\text {conv }} l_{o}}{\rho C_{p} u_{c o} d_{h}}\right)_{i}$

Conduction time number:

$T_{i}^{*}=\left(\frac{\alpha_{s} l_{o}}{\delta^{2} u_{c o}}\right)_{i}$

Biot number:

$B i_{i}=\left(\frac{h_{c o n v} \delta}{k_{s}}\right)_{i}$

Heat source number: 
$Q_{s i}=\left(\frac{\dot{q}_{s} l_{o}}{\rho_{s} C_{p_{s}} u_{c o} \Delta T_{o}}\right)_{i}$

The reference velocity for use with these parameters is the core inlet velocity given by Equation (115). The reference length, $l_{o}$, is the heated height of the core. The reference temperature rise is obtained from an energy balance across the core:

$\Delta T_{o}=\left(\frac{\dot{q}_{s} l_{o}}{\rho C_{p} u_{c o}}\right)\left(\frac{a_{s_{o}}}{a_{o}}\right)$

\subsubsection{Similarity Criteria and Scale Ratios for Single-Phase Natural Circulation}

The similarity criteria for single-phase natural circulation are obtained by setting the model to prototype ratios of each nondimensional parameter equal to unity. Several scale ratios can also be defined.

$\underline{\text { Time constant scale ratio }}$

From the definition of the loop time constant in Equation (103), the time constant scale ratio is given by:

$\tau_{l o o p, R}=\left(\frac{M_{\text {sys }}}{\rho_{l} u_{c o} a_{c}}\right)_{R}=\left(\frac{l_{r e f} \rho_{l} a_{c}}{\rho_{l} u_{c o} a_{c}}\right)_{R}$

where the $R$ subscript represents a model-to-prototype ratio. Substituting the result for $u_{c o}$ from Equation (115),

$\tau_{\text {loop }, R}=\left[\frac{l_{r e f} \rho_{l} a_{c}\left(\rho_{l} a_{c} C_{p l} \Pi_{F l}\right)^{\frac{1}{3}}}{\rho_{l}\left(\beta q_{c o} L_{t h} g\right)^{\frac{1}{3}} a_{c}}\right]_{R}=\left(\frac{\rho_{l} C_{p l}}{\beta}\right)_{R}^{1 / 3}\left(\frac{a_{c} \Pi_{F l}}{q_{c o}}\right)_{R}^{1 / 3}\left(\frac{l_{r e f}}{L_{t h}^{1 / 3}}\right)_{R}$

and if we set assume that $l_{\text {ref }} / L_{t h}$ and $l_{\text {ref }} /$ are the same in the model and the prototype,

$\tau_{l o o p, R}=\left(\frac{\rho_{l} C_{p l}}{\beta}\right)_{R}^{1 / 3}\left(\frac{a_{c} \Pi_{F l} l^{2}}{q_{c o}}\right)_{R}^{1 / 3}$

This result indicates that, for a full-height model, the time constant for the model will be the same as the time constant for the prototype if the same fluid is used (water), the loop resistance number is the same and the core power input to the core cross-sectional area ratio is held constant. The loop resistance number can be independently varied in the model through the use of appropriate added resistance elements (e.g., orifices), so satisfaction of the loop resistance number criterion can be readily achieved.

Fluid velocity scale ratio

Based on the result for $u_{c o}$ from Equation (115),

$u_{R}=\left(\frac{\beta}{\rho_{l} C_{p l}}\right)_{R}^{1 / 3}\left(\frac{q_{c o} l}{a_{c} \Pi_{\mathrm{Fl}}}\right)_{R}^{1 / 3}$

Hence, fluid velocities can be matched in the model based on the same criteria as the loop time constant. This result can also be obtained by dividing the loop length scale ratio by the time constant scale ratio. This result is equivalent to Ishii and Kataoka's (1984) Equation 26.

Loop length scale ratio 
$l_{R}=\left(L_{t h}\right)_{R}$

This condition is satisfied with a geometrically similar full-height model.

Flow area scale ratio

In order to maintain kinematic similarity, the model should be designed to have geometric similarity in terms of cross-sectional flow areas. This requirement can be summarized as:

$\left(\frac{a_{i}}{a_{c}}\right)_{R}=1$

which states that the ratio of each component flow area to the core area should be the same in the model as in the prototype.

Loop resistance scale ratio

Similarity of loop resistance numbers dictates that

$\Pi_{F l, R}=\left[\sum_{i=1}^{N}\left\{\frac{1}{2}\left(\frac{f l}{d_{h}}+K\right)_{i}\left(\frac{a_{c}}{a_{i}}\right)^{2}\right\}\right]_{R}=1$

Frictional and form losses can be varied in the model during the design process by varying the flow crosssectional areas and/or through the use of appropriate orifices.

Loop energy scale ratio

Preservation of the nondimensional loop energy ratio from Equation (110) dictates that the ratio of the temperature difference across the core to the difference between the mixed mean system temperature and the core inlet temperature remain fixed in the model

$E_{R}=\left[\frac{\left(T_{H}-T_{C}\right)_{o}}{\left(T_{M}-T_{C}\right)_{o}}\right]_{R}=1$

$\underline{\text { Steam generator power scale ratio }}$

Preservation of the steam generator transport number (Equation (111)) requires that:

$\left(\frac{q_{S G o}}{q_{c o}}\right)_{R}=1$

Heat loss scale ratio

Similarly, preservation of the loop heat loss number (Equation (112)) requires that:

$\left(\frac{q_{\text {loss }, o}}{q_{\text {co }}}\right)_{R}=1$

Hence, the ratios of the steam generator heat transfer and heat losses to core power should be preserved in the model. It should be noted that the steam generator heat transfer rate and the total loop heat loss are not independent.

Fluid-Solid heat transfer scale ratios

The fluid-solid heat transfer similarity conditions require that: 
$S t_{i_{R}}=T_{i_{R}}^{*}=B i_{i_{R}}=Q_{s_{o_{R}}}=1$

Note that the Stanton number and Biot number ratios both involve a heat transfer coefficient, so the form of the convective heat transfer constitutive relation must be considered.

\subsubsection{Two-Phase Natural Circulation}

\subsubsection{Governing Equations and Nondimensional Parameters for the Primary Loop}

Two-phase natural circulation often appears as an important phenomenon during the progression of design-basis events in reactor systems with respect to loop thermal-hydraulics and primary-to-secondary heat transfer.

Following the scaling analysis presented in Reyes (2005) for two-phase natural circulation, the onedimensional loop momentum balance equation for two-phase natural circulation is given by:

$$
\sum_{i=1}^{N}\left(\frac{l_{i}}{a_{i}}\right) \frac{d \dot{m}}{d t}=g\left(\rho_{l}-\rho_{T P}\right) L_{t h}-\frac{\dot{m}}{\rho_{l} a_{c}^{2}}\left\{\sum_{S P}\left[\frac{1}{2}\left(\frac{f l}{d_{h}}+K\right)\left(\frac{a_{c}}{a_{i}}\right)^{2}\right]+\sum_{T P}\left[\frac{1}{2}\left(\frac{f l}{d_{h}}+K\right)\left(\frac{a_{c}}{a_{i}}\right)^{2}\right]\right\}
$$

This equation is similar to the single-phase loop momentum balance Equation (101), but here the buoyancy term is associated with the density difference between the two phases, and is therefore much stronger than the usual natural convection buoyancy term in which the density difference is due strictly to single-phase thermal expansion. The flow resistance is subdivided into single-phase and two-phase contributions.

The one-dimensional simplified energy equation for two-phase natural circulation is

$M_{\text {sys }} \frac{d\left(e_{M}-e_{l}\right)}{d t}=\dot{m}\left(h_{T P}-h_{l}\right)-q_{S G}-q_{\text {loss }}$

where $e$ represents the specific internal energy. This form of the energy equation is simply a more general version of Equation (102). The left-hand side represents the rate of change of the two-phase system mixed mean internal energy and the right-hand side represents the difference between the heat generation source term and the heat losses in the steam generator and elsewhere.

The local internal energy and enthalpy for two-phase flow requires specification of the local equilibrium vapor quality, $x_{E}$. For example, at the core exit,

$x_{E}=\frac{h_{T P}-h_{f}}{h_{f g}}$

Therefore, the equilibrium fluid specific volume at the core exit is given by

$v_{T P}=v_{f}+x_{E} v_{f g}$

which can be rewritten in terms of local fluid density as

$\rho_{T P}=\frac{\rho_{f}}{1+x_{E}\left(\frac{\rho_{f}-\rho_{g}}{\rho_{g}}\right)}$

For the two-phase system, the momentum and energy equations are nondimensionalized using the loop time constant for the time variable and initial conditions for mass flow rate, flow losses, fluid density, internal energy, enthalpy and heat losses. The loop time constant is again defined by Equation (103). 
The nondimensionalization procedure yields the following nondimensional groups:

$\underline{\text { Loop reference length number }}$

The loop reference length number is the same as for single-phase flow, as provided by Equation (104).

Richardson number

For two-phase flow, the Richardson number has a more general form based on the liquid and vapor densities that appear in the momentum Equation (137):

$R i_{\rho}=\frac{g\left(\rho_{l}-\rho_{T P}\right)_{o} L_{t h}}{\rho_{l} u_{c o}^{2}}$

Hence, the characteristic velocity for buoyancy-driven two-phase flow is given by

$u_{o}=\sqrt{\frac{g\left(\rho_{l}-\rho_{T P}\right)}{\rho_{l}} L_{t h}}$

For two-phase natural circulation, there are two loop resistance numbers.

Loop Liquid-Phase Resistance Number

$\Pi_{\mathrm{F} 1}=\sum_{S P}\left[\frac{1}{2}\left(\frac{f l}{d_{h}}+K\right)\left(\frac{a_{c}}{a_{i}}\right)^{2}\right]$

Loop Two-Phase Resistance Number

$\Pi_{\mathrm{F} 2}=\sum_{T P}\left[\frac{1}{2}\left(\frac{f l}{d_{h}}+K\right)\left(\frac{a_{c}}{a_{i}}\right)^{2}\right]$

The remaining nondimensional parameters for two-phase natural circulation are:

$\underline{\text { Loop energy Ratio }}$

$\Pi_{\mathrm{e}}=\frac{q_{c o}}{\dot{m}_{o}\left(e_{M}-e_{l}\right)_{o}}$

$\underline{\text { Steam generator transport number }}$

$\Pi_{\mathrm{SG}}=\frac{q_{S G o}}{\dot{m}_{o}\left(e_{M}-e_{l}\right)_{o}}$

Loop Heat Loss Number

$\Pi_{\text {Loss }}=\frac{q_{\text {loss }, o}}{\dot{m}_{o}\left(e_{M}-e_{l}\right)_{o}}$

Density Ratio

$\Pi_{\rho}=\frac{\rho_{l}}{\rho_{T P}}$

For steady-state conditions, the nondimensional loop momentum equation for two-phase natural circulation reduces to: 
$R i_{\rho}=\Pi_{F 1}+\Pi_{F 2} \Pi_{\rho}$

Substitution and simplification of this expression for the general case results in a cubic equation for the core inlet velocity.

$u_{c o}^{3}+\varphi_{a} u_{c o}^{2}+\varphi_{b} u_{c o}-\varphi_{c}=0$

where the $\varphi$ coefficients are defined in Reyes (2005). The solution to the system of equations is made tractable by assuming that the liquid is saturated at the core inlet. Invoking this assumption and following the procedure developed by Reyes based on the scaling of "single-state variable catastrophe functions," scale ratios for saturated two-phase natural circulation are obtained (see Equations (156-159)).

\subsubsection{Geometry-Level Governing Equations and Nondimensional Parameters}

Consideration of the governing conservation equations for momentum and energy, including fluid-solid heat transfer, for two-phase flow at the geometry level gives rise to several additional nondimensional parameters (Reyes and Hochreiter 1998, Ishii and Kataoka 1984).

Phase Change number

$\Pi_{\mathrm{pch}}=\frac{4 q_{o}^{\prime \prime} l_{c}}{d_{h} u_{c o} h_{f g} \rho_{f}} \frac{\Delta \rho}{\rho_{g}}$

Subcooling number

$\Pi_{\text {sub }}=\frac{\Delta h_{s u b}}{h_{f g}} \frac{\Delta \rho}{\rho_{g}}$

Froude number

$F r=\frac{u_{T P_{o}}^{2} \rho_{T P}}{\alpha_{o} g l_{o} \Delta \rho_{o}}$

Drift flux number

$\Pi_{N d}=\frac{v_{g j_{o}} \alpha_{o} \Delta \rho_{o}}{u_{T P_{o}} \rho_{T P_{o}}}$

where $v_{g j}$ is the drift velocity.

\subsubsection{Similarity Criteria and Scale Ratios for Two-Phase Natural Circulation}

Scale ratios for saturated two-phase natural circulation can be obtained from scaling of the $\varphi$ coefficients of Equation (151)for the case of no subcooling, following Reyes (1994). The resulting scale ratios, shown in Equations (156-159), below are generally consistent with those of Ishii (1984) and are often also applied to non-saturated conditions.

Fluid velocity scale ratio

Following the Reyes and Hochreiter (1998) derivation, and referring to Equations (143), the velocity scale ratio for two-phase natural circulation is:

$u_{R}=\left(L_{t h}\right)_{R}^{1 / 2}$ 


\section{$\underline{\text { Time constant scale ratio }}$}

The time constant scale ratio is obtained by dividing the length scale ratio by the velocity scale ratio:

$\tau_{\text {loop }, R}=\frac{l_{R}}{\left(L_{t h}\right)_{R}^{1 / 2}}$

$\underline{\text { Core power scale ratio }}$

$\left(q_{c o}\right)_{R}=a_{c, R}\left(L_{t h}\right)_{R}^{1 / 2}\left(\frac{\rho_{f} \rho_{g} h_{f g}}{\Delta \rho}\right)_{R}$

This expression for core power scale ratio is equivalent to the phase change number ratio, as derived from Equation (85) of Ishii and Kataoka's (1984), with $u_{R}=L_{t h, R}{ }^{1 / 2}$.

Flow area scale ratio

The flow area scale ratio given by Equation (131) is still applicable.

$\underline{\text { Steam generator power scale ratio }}$

The steam generator power scale ratio given by Equation (134) is still applicable.

Heat loss scale ratio

The heat loss scale ratio given by Equation (135) is still applicable.

$\underline{\text { Loop resistance scale ratios }}$

The scaled facility should be designed such that the single-phase and two-phase friction numbers are as close to those of the prototype as possible, such that:

$\left(\Pi_{F 1}\right)_{R}=\left(\Pi_{F 2}\right)_{R} \approx 1$

Phase Change number ratio

With fluid properties matched between the model and the prototype, the phase change number ratio becomes:

$\Pi_{\mathrm{pch}_{\mathrm{R}}}=\left(\frac{q_{o}^{\prime \prime} l_{o}}{d_{h} u_{o}}\right)_{R}$

$\underline{\text { Subcooling number ratio }}$

With matched fluid properties, the subcooling number ratio becomes simply:

$\Pi_{\mathrm{Sub}_{\mathrm{R}}}=\Delta h_{\mathrm{sub}_{R}}$

Froude number scale ratio

For the case of equal fluid properties, Froude number similarity reduces to:

$F r_{R}=\left(\frac{u_{T P_{o}}^{2}}{\alpha_{o} l_{o}}\right)_{R}$

Drift flux number scale ratio

For the case of equal fluid properties, the drift flux scale ratio is given by: 
$\Pi_{N d_{R}}=\left(\frac{v_{g j} \alpha_{o}}{u_{T P_{o}}}\right)_{R}$

\subsection{Bottom-Up Scaling Analysis}

The H2TS methodology requires bottom-up scaling analyses focusing on important local phenomena needed to enable evaluation of several scale ratios and nondimensional groups that result from the top-down analysis. Phenomena to be considered typically include single and two-phase friction losses and loss coefficients, flow regime transitions, core two-phase flow processes, three-dimensional (3D) effects, and effects of noncondensables. These phenomena can be studied and evaluated via detailed phenomenological modeling or separate effects testing and appropriate localized nondimensional parameters can be identified and evaluated.

\subsubsection{Single-Phase Natural Circulation}

For single-phase natural circulation, bottom-up scaling analysis is performed to evaluate the loop frictional losses and loss coefficients, using appropriate correlations or RELAP5-3D analysis. Once the losses are quantified, the loop resistance number and Richardson number can be evaluated and the core inlet velocity can be obtained from Equation (115), as a function of core power. Individual friction losses for each loop component can be quantified through careful development of a RELAP5-3D model of the loop. Comparison of experimental results with RELAP5-3D predictions can provide insights into the magnitude of the single-phase loss coefficients associated with the loop and the accuracy of the RELAP5-3D representation of those losses. The results can also provide guidance for possible modifications (e.g., addition of orifice plates) to the experimental loop for improved scaling, if needed.

During reactor design-basis scenarios, natural circulation is driven by decay heat and stored thermal energy in the fuel and other materials. The decay heat and the effect of stored thermal energy, along with the heat transfer characteristics of the core together determine the transient response of the system, including single- and two-phase natural circulation. In the model, proper simulation of early-stage transients requires knowledge of both the time-dependent decay heat and the effect of stored thermal energy since electrically heated "fuel rods" have different thermal energy storage characteristics than actual fuel rods. Once steady-state natural circulation data are acquired, transient heating tests (heatup and cooldown) can be performed over a range of core power values to determine the transient heating characteristics of the electrically heated core. These results will provide guidance for improvement of the RELAP5-3D representation of the electrically heated core and, when compared to the transient characteristics of the prototypic core, will provide guidance for determination of appropriate power profiles needed for testing.

\subsubsection{Two-Phase Natural Circulation}

\subsubsection{Two-Phase Friction and Loss Coefficients}

Two-phase natural circulation can occur in the reactor during design-basis scenarios. Bottom-up scaling analysis is needed to evaluate two-phase friction and form loss coefficients, steam generator heat transfer, and interconnecting pipe heat loss. In addition, an assessment of two-phase flow patterns may be needed for each component. 
Two-phase natural circulation similarity criteria include the requirement that two-phase loop resistance numbers be matched between the model and the prototype. Following Reyes and Hochreiter (1998) and Ishii and Kataoka (1984), (based on Collier 1972) the two-phase flow resistances can be subdivided into a frictional component and a form loss component.

$\Pi_{\mathrm{F} 2}=\sum_{T P} N_{f i}+\sum_{T P} N_{K i}$

The homogeneous two-phase friction factor model and the outlet orifice pressure drop model from Collier (1972) (Sections 2.3.2 and 3.8.3) can then be applied, yielding

$N_{f i}=\frac{f l}{d_{h}}\left[\frac{1+\Delta \rho x / \rho_{g}}{\left(1+\Delta \mu x / \mu_{g}\right)^{1 / 4}}\right]\left(\frac{a_{c}}{a_{i}}\right)^{2}$

and

$N_{K i}=K\left(1+\frac{\Delta \rho x^{3 / 2}}{\rho_{g}}\right)\left(\frac{a_{c}}{a_{i}}\right)^{2}$

where $f$ is the Darcy friction factor for the liquid and $K$ is the form loss coefficient. These equations indicate the importance of density and viscosity ratios and exit vapor quality for each component. The fluid property ratios should be satisfied in fluid-matched facilities. For natural circulation flows, form losses will dominate. Therefore, the modeling of the loss coefficients is also critical. Furthermore, the loss coefficients for each component in the model should be scaled to match the expected prototypic loss coefficients. This issue can be addressed in the experimental facility through the use of near-prototypic geometrically similar components and through operation at full pressure, full temperature, with prototypic core heat flux. Scaled core power in the heated section should produce a prototypic vapor quality distribution. For other components, control of heat losses will be critical. Heat fluxes in the steam generator (or heat removal section) should be near prototypic, so the primary-side vapor quality distribution in the steam generator tubes should also be near prototypic.

\subsubsection{Two-Phase Flow Pattern and Transitions}

For small modular reactor systems, consideration of two-phase flow regimes need only consider vertical geometries since there are effectively no horizontal pipe runs in the system. Relevant transitions include bubbly-to-slug, slug-to-churn, and slug/churn-to-annular flow. Based on the analysis presented in Schwartzbeck and Kocamustafaogullari (1989), summarized in Reyes and Hochreiter (1998), these transitions will be properly scaled if the following criteria are satisfied.

Bubbly-to-slug flow:

$\alpha_{\mathrm{R}}=\left(\frac{\rho_{f}}{\Delta \rho}\right)_{R}=1$

This criterion is satisfied automatically for a full-pressure model with the same working fluid.

Slug-to-churn flow:

$l_{R}=a_{R}^{1 / 2} f_{T}(x, \rho)$

This expression conveys the general vertical length scale requirement for this transition that $l_{R} \sim a_{R}^{1 / 2}$ for the vertical sections of the model, which is not consistent with a full-height, reduced-area model. However, full-pressure models can simulate this transition with a full-height model model (Schwartzbeck and Kocamustafaogullari 1989). The functional relationship $f_{T}(x, \rho)$ in Equation (168) is discussed in detail and presented graphically in Schwartzbeck and Kocamustafaogullari 1989. 


\section{Slug/churn to annular flow:}

$u_{R}\left(\frac{\rho_{g}^{2}}{\sigma \Delta \rho}\right)_{R}^{1 / 4}=1$

If the velocity scale ratio is 1 and fluid properties are matched, this flow pattern criterion is satisfied.

\subsubsection{Core Heat Transfer}

Critical heat flux (CHF) scaling can also be examined. Reyes and Hochreiter (1998) and Ishii and Kataoka (1984) used the Katto "L-regime" correlation [9] to examine low-flow CHF scaling. This correlation applies to dryout-type CHF. The correlation has the form:

$q_{C H F}^{\prime \prime}=\frac{G_{c} h_{f g} d_{h, c}}{4 l_{c}}\left[\left(\frac{\sigma \rho_{f}}{G_{c}^{2} l_{c}}\right)^{0.043}+\frac{h_{s u b}}{h_{f g}}\right]$

This correlation, which was developed for low-flow two-phase natural circulation, can be used as the basis for CHF scaling (Reyes and Hochreiter 1998). In this equation, the mass flux and core channel hydraulic diameter are given by:

$G_{c}=\frac{\dot{m}_{c}}{a_{c}}$ and $d_{h, c}=\frac{4\left[s^{2}-\pi d_{p i n}^{2} / 4\right]}{\pi d_{p i n}}$

The following CHF scaling criterion can be adopted:

$\Pi_{C H F, R}=\left(\frac{q_{C H F}^{\prime \prime}}{q_{C, R O D}^{\prime \prime}}\right)_{R}=1$

where

$q_{c, R O D}^{\prime \prime}=\frac{F_{q} q_{c}}{N \pi d l_{c}}$

In this equation, $F_{q}$ is the axial heat flux distribution peaking factor (typically $\sim 1.5$ ). This scaling criterion specifies that the ratio of critical heat flux to peak core heat flux should be the same for the model and in the prototype, specifically for two-phase natural circulation situations. Combining Equation (170) and Equation (173), for the case of the same working fluid and same pressure, the scaling criterion becomes

$\frac{N_{R} d_{R}\left(d_{h, c}\right)_{R} G_{c, R}}{\left(F_{q}\right)_{R} q_{R}}\left[\left(\frac{\sigma \rho_{f}}{G_{c}^{2} l_{c}}\right)^{0.043}+\frac{h_{s u b}}{h_{f g}}\right]_{R}=1$

The applicability for this correlation is limited to Katto's (1978) "L-regime". The parameter range of applicability for this correlation is given by:

$\frac{L}{d_{h}}>\frac{1}{0.4\left(\frac{\rho_{g}}{\rho_{f}}\right)^{0.133}\left(\frac{\sigma \rho_{f}}{G_{c}^{2} l_{c}}\right)^{0.29}-0.0031}$ 


\subsubsection{Two-Phase Drift Velocity}

Based on Ishii's (1977) equation for drift velocity $v_{g j}$ (Kocamustafaogullari and Ishii 1984), the nondimensional drift flux number (Equation [155]) becomes

$\Pi_{N d}=\left\{0.2\left[1-\left(\frac{\rho_{g}}{\rho_{f}}\right)^{1 / 2}\right]\left[1+x\left(\frac{\Delta \rho}{\rho_{g}}\right)\right]+\frac{1.4}{u_{c}}\left(\frac{\sigma g \Delta \rho}{\rho_{f}^{2}}\right)^{1 / 4}\right\} \frac{\alpha_{o} \Delta \rho_{o}}{\rho_{T P_{o}}}$

The scaling requirement for drift velocity can be stated simply as $\Pi_{N d, \mathrm{R}}=1$. The first term in Equation (176) represents distributed slip and the second term represents local slip, which is generally small compared to distributed slip. The first term is automatically satisfied by fluid property similarity. In cases where local slip is important, the similarity requirement is $u_{R}=1$. Even in local regions where some velocity distortion occurs, the distortion of the velocity introduces only limited changes in the void-quality relation (Kocamustafaogullari and Ishii 1984).

\subsection{System Depressurization Scaling Analysis}

Many design-basis transients for reactor systems ultimately result in system depressurization. It follows that all the principal phenomena of rank are also represented. In the investigation of system depressurization phenomena, observations of break flow, pressurizer mass/energy transport, and steam generator primary/secondary heat transfer are possible in the scaled facility. Consequently, proper scaling of the depressurization process is an important consideration in its design and operation. For reduced-pressure scaled facilities, the initial state of the full-scale system cannot be duplicated and a method must be developed to define appropriate initial and final boundary conditions such that the evolution of the transient is correct on a scaled basis (Reyes and Hochreiter 1998). The situation is simpler with a full-pressure, full-temperature facility.

The mass conservation equation for a constant-volume system is given by:

$\frac{d M_{s y s}}{d t}=\sum \dot{m}_{\text {in }}-\sum \dot{m}_{\text {out }}$

The energy equation, combined with mass conservation, can be rearranged to yield the one-dimensional depressurization rate equation for a control volume with rigid boundaries (Reyes and Hochreiter 1998):

$M_{\text {sys }}\left(\frac{\partial e}{\partial P}\right)_{v} \frac{d P}{d t}=\sum \dot{m}_{\text {in }}\left[h_{\text {in }}-e+v\left(\frac{\partial e}{\partial v}\right)_{P}\right]-\sum \dot{m}_{\text {out }}\left[h_{\text {out }}-e+v\left(\frac{\partial e}{\partial v}\right)_{P}\right]+\dot{q}_{N e t}$

These equations can be nondimensionalized by normalizing with respect to initial break conditions, yielding:

$\tau_{s y s} \frac{d M_{s y s}^{+}}{d t}=\Pi_{m} \sum \dot{m}_{i n}^{+}-\sum \dot{m}_{o u t}^{+}$

and 


$$
\begin{aligned}
\tau_{\text {sys }} \epsilon_{o} M_{\text {sys }}^{+}\left(\frac{\partial e}{\partial P}\right)^{+} & \left(\frac{d P^{+}}{\partial t}\right) \\
& =\Pi_{h} \sum \dot{m}_{\text {in }}^{+}\left[h_{\text {in }}-e+v\left(\frac{\partial e}{\partial v}\right)_{P}\right]^{+} \\
& -\sum \dot{m}_{\text {out }}^{+}\left[h_{\text {out }}-e+v\left(\frac{\partial e}{\partial v}\right)_{P}\right]^{+}+\Pi_{\Gamma} \dot{q}_{N e t}^{+}
\end{aligned}
$$

These nondimensional mass and energy conservation equations introduce four new nondimensional parameters:

$\underline{\text { Characteristic time ratio }}$

$\Pi_{m}=\frac{\sum \dot{m}_{i n, o}}{\sum \dot{m}_{\text {out }, o}}$

Dilation

$\epsilon_{o}=\frac{P_{o}\left(\frac{\partial e}{\partial P}\right)_{v, o}}{\left[h_{o u t}-e+v\left(\frac{\partial e}{\partial v}\right)_{P}\right]_{O}}$

Energy flow ratio

$\Pi_{h}=\frac{\Sigma \dot{m}_{\text {in }, o}\left[h_{\text {in }}-e+v\left(\frac{\partial e}{\partial v}\right)_{P}\right]_{o}}{\Sigma \dot{m}_{\text {out }, o}\left[h_{\text {out }}-e+v\left(\frac{\partial e}{\partial v}\right)_{P}\right]_{o}}$

$\underline{\text { Power ratio }}$

$\Pi_{\Gamma}=\frac{\dot{q}_{N e t, o}}{\Sigma \dot{m}_{\text {out }, o}\left[h_{\text {out }}-e+v\left(\frac{\partial e}{\partial v}\right)_{P}\right]_{o}}$

The characteristic time ratio is the system mass flow rate ratio. It determines the rate of change of system mass inventory. Dilation is an energy ratio that couples the system internal energy change with the internal energy at the break. The energy flow ratio represents the ratio of the system energy increase due to fluid injection to the system energy decrease associated with the break. The power ratio represents the ratio of the net heat input to the system (e.g., decay heat) to the rate of energy loss associated with fluid transport through the break.

An additional parameter that appears in both conservation equations is the residence time constant:

$\tau_{\text {sys }}=\frac{M_{\text {sys }, o}}{\Sigma \dot{m}_{\text {out }, o}}=\frac{\rho_{T P o} V_{T P o}}{\sum C_{d} G_{\text {out }} a_{\text {brk }}}$

where $C_{d}$ is the break discharge coefficient, $G_{\text {out }}$ is the break mass flux, and $a_{b r k}$ is the break flow area.

For a full-height, reduced-area model, with a flow-area scale factor (model to prototype) of $A_{R}$, matching of the residence time constant for the model requires scaling of the break flow rate such that:

$\tau_{\text {sys }, R}=1=\left[\frac{\rho_{T P o}}{\Sigma C_{d} G_{\text {out }} a_{\text {brk }}}\right]_{R} V_{R}=\left[\frac{\rho_{T P o}}{\Sigma C_{d} G_{\text {out }} a_{\text {brk }}}\right]_{R} A_{R}$

which yields 
$\left[\frac{\sum C_{d} G_{\text {out }} a_{\text {brk }}}{\rho_{\text {TPo }}}\right]_{R}=A_{R}$

This result and matching of the characteristic time ratio dictate the scaling of the injection flow rates from the intermediate pressure accumulator tanks and the passive gravity-fed injection from the elevated core makeup tanks.

$\Pi_{m, R}=1=\left[\frac{\Sigma G_{\text {in }} a_{\text {in }}}{\Sigma C_{d} G_{\text {out }} a_{\text {brk }}}\right]_{R}=\left[\frac{\sum G_{\text {in }} a_{\text {in }}}{\rho_{T P o} A_{R}}\right]_{R}$

which results in:

$\left[\frac{\sum G_{\text {in }} a_{\text {in }}}{\rho_{\text {TPo }}}\right]_{R}=A_{R}$

Equation (182) for dilation is valid for saturated conditions at the break. Based on this equation, dilation is dependent only on system pressure and fluid properties. For the case of a full-pressure, fulltemperature model with the same working fluid,

$\epsilon_{o, R}=1$

The energy flow ratio scaling is represented by:

$\Pi_{h, R}=\left\{\frac{\Sigma \dot{m}_{\text {in }, o}\left[h_{\text {in }}-e+v\left(\frac{\partial e}{\partial v}\right)_{P}\right]_{o}}{\Sigma \dot{m}_{\text {out }, o}\left[h_{\text {out }}-e+v\left(\frac{\partial e}{\partial v}\right)_{P}\right]_{o}}\right\}_{R}=\Pi_{m, R}\left\{\frac{\left[h_{\text {in }}-e+v\left(\frac{\partial e}{\partial v}\right)_{P}\right]_{o}}{\left[h_{\text {out }}-e+v\left(\frac{\partial e}{\partial v}\right)_{P}\right]_{o}}\right\}_{R}=1$

This criterion is also satisfied on the basis of fluid property matching, assuming the characteristic time ratio, $\Pi_{m, R}$ is equal to 1 .

The power ratio scaling criterion is given by:

$\Pi_{\Gamma, R}=\left\{\frac{\dot{q}_{\text {Net }, o}}{\sum \dot{m}_{\text {out }, o}\left[h_{\text {out }}-e+v\left(\frac{\partial e}{\partial v}\right)_{P}\right]_{o}}\right\}_{R}=1$

Satisfaction of this criterion requires proper scaling of the decay heat and break flow rate (Equation (188)). The magnitude of the power ratio can be estimated by assuming critical flow at the break and invoking an appropriate critical flow model such as the Henry-Fauske model (1971). According to this model, the critical flow rate at the break is given by:

$G_{c}=\left[\frac{x_{o} v_{g}}{n P}+\left(v_{g}-v_{f o}\right)\left\{\frac{\left(1-x_{o}\right) N}{s_{g, E}-s_{f, E}} \frac{d s_{l, E}}{d P}-\frac{x_{o} c_{p g}(1 / n-1 / \gamma)}{P\left(s_{g o}-s_{f o}\right)}\right\}\right]^{-1 / 2}$

where $\mathrm{n}$ is the thermal equilibrium polytropic exponent given by:

$n=\frac{(1-x) c_{p f} / c_{p g}+1}{(1-x) c_{p f} / c_{p g}+1 / \gamma}$

and $N$ is an empirical value. For $x_{E}>0.14, N=1$ and for $x_{E}<0.14, N=x_{E} / 0.14$.

Using Equation (193), the break mass flow rate and the corresponding power ratio can be estimated as a function of break diameter. This calculation has been performed for early break conditions in a reactor system, assuming saturated conditions in the primary system with a pressure of 2,000 psi, 
$T_{\text {sat }}=635.8^{\circ} \mathrm{F}$ and a vapor quality of 0.05 and a decay heat value of $5 \%$. Results are presented in Figure 12. The figure indicates that, for large breaks $\left(D_{b r k}>\sim 2 \mathrm{in}\right.$.), the value of the power ratio is less than 1.0 and the break flow rate will dominate the depressurization rate. For small breaks, the power ratio can be very large, while the system mass flow rate and energy flow rate ratios are very small (or zero). For these conditions, the decay heat and the resultant system vapor generation rate will dominate the depressurization rate.

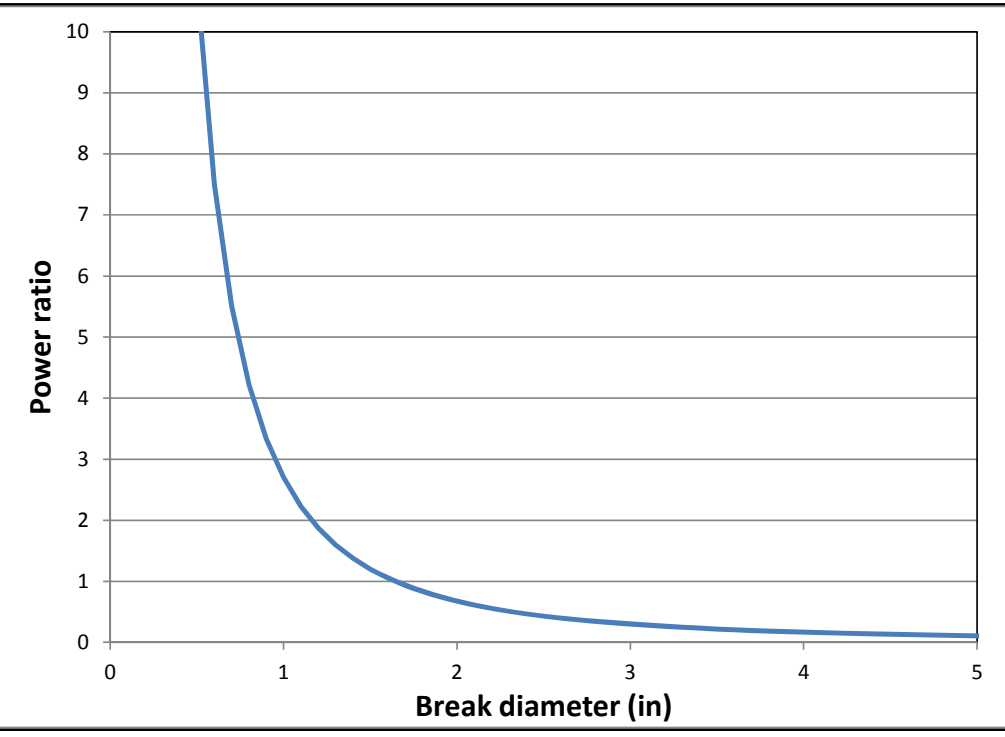

Figure 12. Power ratio as a function of break diameter. 


\section{CONCLUSIONS}

Hybrid energy system research has the potential to significantly expand the application for nuclear reactor technology beyond electricity, reducing both technical and economic risks associated with energy systems of the future. NHES mitigates the variability of renewable energy sources, provides opportunities to produce revenue from different product streams, and avoids capital inefficiencies by matching electrical output to demand by using excess generation capacity for other purposes when it is available. An essential step in the commercialization and deployment of this advanced technology is scaled testing

to demonstrate integrated dynamic performance of advanced systems and components when risks cannot be mitigated adequately by analysis or simulation. Further testing in a prototypic environment is needed for validation and higher confidence.

A component test capability such as the ARTIST facility can support cross-cutting research for various DOE programs. Testing in the prototypic environment becomes a fundamental element of effective risk management for further development of NHES and advanced reactor technology programs. The scaling analysis presented in this report can be applied to single- and two-phase thermal hydraulic systems, modified as needed depending on the components included in the system of interest and the modes of operation.

This research supports the development of advanced nuclear reactor technology and NHES, and their adaptation to commercial industrial applications that will potentially advance U.S. energy security, economy, and reliability and further reduce carbon emissions. Experimental infrastructure development for testing and feasibility studies of coupled systems can similarly support other projects having similar developmental needs and can generate data required for validation of models in thermal energy storage and transport, energy, and conversion process development. Experiments performed in the Systems Integration Laboratory will acquire performance data, identify scalability issues, and quantify technology gaps and needs for various hybrid or other energy systems.

Detailed scaling (component and integrated system) and heat transfer figures of merit as defined in this document, can be used to establish the experimental infrastructure for component, subsystem, and integrated system testing to advance the technology readiness of components and systems to the level required for commercial application and demonstration under NHES. 


\section{REFERENCES}

1. Bejan, A., Tsatsaronis, G., and Moran, M., 1996, "Thermal Design and Optimization,” John Wiley \& Sons.

2. Bhattarai, B. P., Bak-Jensen, B., Pillai, J. R., Gentle, J. P., and Myers, K. S., 2015, "Overvoltage Mitigation using Coordinated Control of Demand Response and Grid-tied Photovoltaics," SusTech2015. Odgen: IEEE.

3. Bonilla, C. F., 1958, “Comparisons of Coolants," Section 9-3, Chapter 6.5, Nuclear Engineering Handbook, Ed. H. Etherington, McGraw-Hill, NY.

4. Bragg-Sitton, S. M., Boardman, R., Wood, R., Garcia, H., McKellar, M., Sabharwall, P., and Rabiti, C., 2013, Value Proposition for Load-Following Small Modular Reactor Hybrid Energy Systems, INL/EXT-13-29298, May 2013.

5. Carlson, R. W., and Normann, B., 2014, "Test Results of the PLUGLESS ${ }^{\mathrm{TM}}$ Inductive Charging System from Evatran Group Inc.," SAE World Congress 2014, SAE International, pp. 64-71.

6. Collier, J. G., 1972, Convective Boiling and Condensation, McGraw-Hill, New York, 1972.

7. Collins, J.W., 2009, Next Generation Nuclear Plant Project Technology Development Roadmaps: The Technical Path Forward for 750-800 ${ }^{\circ} \mathrm{C}$ Reactor Outlet Temperature, INL/EXT-09-16598, August 2009.

8. Henry, R. E., and Fauske, H. K., 1971, "The two-phase critical flow of one-component mixtures in nozzles, orifices, and short tubes," J. Heat Transfer., Vol. 93, No. 2, pp. 179-187, 1971.

9. INL, 2013, PLUGLESS TM Level 2 EV Charging System (3.3kW) by Evatran Group Inc. Retrieved March 23, 2015, from Advanced Vehicle Testing Activity AVTA:

http://avt.inel.gov/pdf/evse/EvatranWirelessChargingFactsheetAug2013.pdf, August 2013.

10. Ishii, M., 1977, One-Dimensional Drift-Flux Model and Constitutive Equations for Relative Motion between Phases in Various Two-Phase Flow Regimes, Argonne National Laboratory Report, ANL-77-47, 1977.

11. Ishii, M., and Kataoka, I., 1984, "Scaling Laws for Thermal-Hydraulic System Under Single Phase and Two-Phase Natural Circulation," Nuclear Engineering and Design, Vol. 81, pp. 411-425, 1984.

12. Katto, Y., 1978, "A Generalized Correlation of Critical Heat Flux for the Forced Convection Boiling in Vertical Uniformly Heated Round Tubes," Int. J. Heat Mass Transfer, Vol. 21, pp. 1527-1542, 1978.

13. Kim, E.S., Sabharwall, P., and Anderson, N., 2011, "Development of Figure of Merits (FOMs) for Intermediate Coolant Characterization and Selection," Proceedings of the 2011 National American Nuclear Society Conference, Hollywood, Florida, June 26-30, 2011.

14. Kocamustafaogullari, G., and Ishii, M., 1984, "Scaling criteria for two-phase flow loops and their application to conceptual 2 x 4 simulation loop design," Nuclear Technology, Vol. 65, No. 1, pp. 146-160.

15. Larson, T. K., Moody, F. J., Wilson, G. E., Brown, W. L., Frepoli, C., Hartz, J., Woods, B. G., and Oriani, L., 2007, "Iris Small Break LOCA Phenomena Identification and Ranking Table (PIRT)," Nuclear Eng. and Design, Vol. 237, pp. 618-626.

16. Muljadi, E., Singh, M., Gevorgian, V., Mohanpurkar, M., Hovsapian, R. and Koritarov, V., 2015, "Dynamic Modeling of Adjustable-Speed Pumped Storage Hydropower Plant," IEEE PES General Meeting, July 2015, pp. 6. 
17. O’Brien, J.E., Sabharwall, P., Yoon S.J., and Housley, G.K., 2014, Strategic Need for MultiPurpose Thermal Hydraulic Loop for Support of Advanced Reactor Technologies, INL/EXT-1433300, September 2014.

18. Ostrom, L., 2015, "Demonstrating Hybrid Heat Transport and Energy Conversion System Performance Characterization Using Intelligent Control System," NEUP12-3510 Hybrid Energy Conversion FY2014 Progress Report, University of Idaho, March 2015.

19. Panwar, M., Mohanpurkar, M., Osorio, J. D., and Hovsapian, R., 2015, "Significance of Dynamic and Transient Analysis in the Design and Operation of Hybrid Energy Systems," Proceedings of the 9th International Topical Meeting on Nuclear Plant Instrumentation, Control, and Human Machine Interface Technologies, Charlotte, North Carolina, February 2015, pp. 10.

20. Reyes, J. N., 2005, "Integral System Experiment Scaling Methodology," Annex 11 of Natural circulation in water cooled nuclear power plants, IAEA-TECDOC-1474, November 2005.

21. Reyes, J. N., and Hochreiter, L., 1998, "Scaling Analysis for the OSU AP600 Test Facility (APEX)," Nuclear Engineering and Design, Vol. 186, pp. 53-109.

22. Reyes, J. N., 1994, "Scaling Single State Variable Catastrophe Functions: An Application to Two Phase Natural Circulation," Nuclear Engineering and Design, Vol. 151, pp. 41-48.

23. Ruth, M. F., Owen, R. Z., Antkowiak, M., Boardman, R. D., Cherry, R. S., and Bazilian, M. D., 2014, "Nuclear-renewable hybrid energy systems: Opportunities, interconnections, and needs," Energy Conversion and Management, Vol. 78, pp.684-694.

24. Sabharwall, P., Kim, E. S., McKellar, M., Anderson, N., and Patterson, P., 2011, Process Heat Exchanger Options for the Advanced High Temperature Reactor, INL/EXT-11-21584, June 2011.

25. Sabharwall, P., Kim, E.S., Siahpush, A., Anderson, N.A., Glazoff, M., Phoenix, W., Mizia, R., Clark, D., McKellar, M., and Patterson, M., Feasibility Study of Secondary Heat Exchanger Concepts for the Advanced High Temperature Reactor, INL/EXT-11-23076, September 2011.

26. Schwartzbeck, R. K., and Kocamustafaogullari, G., 1989, "Similarity Requirements for Two-Phase Flow Pattern Transitions," Nuclear Engineering and Design, Vol. 116, pp. 135-147.

27. Bragg-Sitton, S.M., Sabharwall, P., and Boardman, R. D., 2014, "Nuclear Hybrid Energy Systems: Challenges and Opportunities," $8^{\text {th }}$ International Youth Nuclear Congress (IYNC2014), Burgos, Spain, July 6-12, 2014.

28. Welty, J. R., Wicks, C. E., and Wilson, R. E., 1984, "Fundamentals of Momentum, Heat, and Mass Transfer,” John Wiley \& Sons, 1984.

29. Williams, D. F., 2006, "Assessment of Candidate Molten Salt Coolants for the NGNP/NHI HeatTransfer Loop,” ORNL/TM-2006/69.

30. Zuber, N., 1991, "Appendix D: Hierarchical, Two-Tiered Scaling Analysis," An Integrated Structure and Scaling Methodology for Severe Accident Technical Issue Resolution, U.S. Nuclear Regulatory Commission, NUREG/CR-5809, November 1991. 